\title{
LIFE CYCLE AND EPIDEMIOLOGY OF \\ Amblyospora sp. (MICROSPORA: THELOHANIIDAE) \\ IN THE MOSQUITO CuleX salinarius COQUILLETT
}

\section{By}

THEODORE GEORGE ANDREADIS

A DISSERTATION PRESENTED TO THE GRADUATE COUNCIL OF THE UNIVERSITY OF FLORIDA

IN PARTIAL FULFILLMENT OF THE REQUIREMENTS FOR THE DEGREE OF DOCTOR OF PHILOSOPHY

UNIVERSITY OF FLORIDA

1978 



\section{ACKNOWLEDGMENTS}

I would like to express my sincere appreciation to Dr. D. W. Hall for his continual advice, encouragement and friendship throughout the course of this study.

I would like to thank Mr. E. I. Hazard of the Insects Affecting Man and Animals Research Laboratory, USDA, Gainesville, Florida, for his assistance in interpreting many aspects of the life cycle.

Special thanks are extended to Mrs. S. W. Avery and Miss E. A. Ellis, also of the Gainesville lab, for their assistance in the ultrastructural studies.

I would also like to acknowledge Dr. T. J. Walker and Dr. J. L. Nation for their critical appraisal of the dissertation.

Finally, I would like to thank the entire staff of the Insects Affecting Man and Animals Research Laboratory who graciously provided research space and facilities without which this study would not have been possible. 
TABLE OF CONTENTS

Page

ACKNOWLEDGMENTS . . . . . . . . . . . . . . . . . . . . . . . i i

LIST OF TABLES . . . . . . . . . . . . . . . . . v v

LIST OF FIGURES . . . . . . . . . . . . . . . . . . . . vi

ABSTRACT . . . . . . . . . . . . . . . . . . . . . . ix

INTRODUCTION . . . . . . . . . . . . . . . . . . . . . . 1

LITERATURE REVIEW . . . . . . . . . . . . . . . . . 3

The Microsporidia . . . . . . . . . . . . . . 3

Definition and taxonomic status .......... . . 3

Structure .................... 3

General scheme of the life cycle . . . . . . . . 5

Transmission . . . . . . . . . . . . . . 6

Effects of microsporidian infections on their 7

insect hosts.................

Genus Amblyospora Hazard and 0ldacre . . . . . . . . . 9

DEVELOPMENT, ULTRASTRUCTURE AND MODE OF TRANSMISSION OF

Ambl yospora sp. (MICROSPORA: THELOHANI IDAE) IN THE

MOSQUITO Culex sal inarius COQUILLETT . . . . . . . . . . . 11

Abstract ....................... . . . 11

Introduction . . . . . . . . . . . . . . . . 11

Materials and Methods . . . . . . . . . . . . 13

Results......................... . . 14

Discussion . . . . . . . . . . . . . . . . 17 
SIGNIFICANCE OF TRANSOVARIAL INFECTIONS OF Amblyospora sp.

(MICROSPORA: THELOHANIIDAE) IN RELATION TO PARASITE MAIN-

TENANCE IN THE MOSQUITO CuTeX salinariuS COQUILLETT . . . . . . 37

Abstract ................ . . . 37

Introduction .................... 37

Materials and Methods .............. 39

Results and Discussion..................... 41

REFERENCES ...................... 52

BIOGRAPHICAL SKETCH ............... 58 


\section{LIST OF TABLES}

Table

Page

1 Physiological longevity of heal thy and Amblyospora sp.infected $\mathrm{C}$. salinarius ........... 45

2 Egg production and hatch during each gonotrophic cycle for heal thy and Amblyospora sp.-infected $\underline{\text {. }}$ salinarius. . 46

3 Developmental periods for heal thy and Amblyospora sp.infected C. salinarius........... . 47

4 Survival rates for heal thy and Amblyospora sp.infected . . salinarius............ 48

5 Prevalence rate of infection among adult female progeny produced by infected females with each gonotrophic cycle................. 49 


\section{LIST OF FIGURES}

Figure

Page

$1 \quad$ Life cycle of Amblyospora sp. in C. salinarius. . . . 22

2 Photomicrograph of a primary diplokaryon ....... 24

3 Photomicrograph of a dividing diplokaryon . . . . . 24

4 Photomicrograph of a dividing diplokaryon . . . . . 24

5 Photomicrograph of an intermediate diplokaryon . . . 24

6 Photomicrograph of a secondary diplokaryon

from the female host............. 24

7 Photomicrograph of a dividing diplokaryon

from the female host............ 24

8 Photomicrograph of divided diplokarya from

the female host................. 24

9 Photomicrograph of a sporoblast from the

female host.............. . . . 24

10 Photomicrograph of a mature spore from

the female host.............. . . 24

11 Photomicrograph of a secondary diplokaryon from

the male host.................... 24

12 Photomicrograph of a dividing diplokaryon from

the male host.................... 24

13 Photomicrograph of a dividing diplokaryon

from the male host ............. 24

14 Photomicrograph of a dividing diplokaryon

from the male host ..............

15 Photomicrograph of a binucleate sporont

from the male host ............ . . 24

16 Photomicrograph of a quadrinucleate

sporont from the male host .......... . . 24 
17 Photomicrograph of an octonucleate sporont from the male host............ 24

18 Photomicrograph of a pansporoblast with eight sporoblasts from the male host........ 24

19 Photomicrograph of spores in a pansporoblast membrane from tine male host . . . . . . . . . 24

20 Photomicrograph of mature spores from the male host..............24

21 Photomicrograph of macrospores from the male host............... 24

22 Sagittal section of a fourth instar male larva of C. salinarius infected with Amblyospora sp.

23 Amblyospora sp.-infected oenocyte containing diplokarya lying next to the ovaries of a newly emerged adult female $\underline{C}$. salinarius . . . . . 26

24 Amblyospora sp.-infected oenocyte containing mature spores in close association with the developing oocytes of an adult $C$. Salinarius female $48 \mathrm{hr}$ after a blood meal ........ 26

25 Electron micrograph of a binucleate sporoplasm from the hoemocoel of an adult female..... . 28

26 Electron micrograph of an infected oenocyte containing secondary diplokarya from a recently emerged adult female........... 28

27 Electron micrograph of a secondary diplokaryon from the female host.......... 28

28 Electron micrograph of a young sporoblast from an adult female $42 \mathrm{hr}$ following a blood meal

29 Electron micrograph of a mature sporoblast from an adult female $44 \mathrm{hr}$ following a blood meal

30 Electron micrograph of a mature spore from an adult female $48 \mathrm{hr}$ following a blood meal .... 30

31 Electron micrograph of a mature spore discharging its sporoplasm in an adult female $60 \mathrm{hr}$ following a blood meal 
32 Electron micrograph of an oenocyte from a first instar male larva containing diplokarya . . . . 30

33 Electron micrograph of a diplokaryon from the fatbody of a first instar male larva ...... 32

34 Electron micrograph of a diplokaryon in the state of mitotic division from the male host................ 32

35 Electron micrograph of a secondary diplokaryon from the male host .......... 32

36 Electron micrograph of a diplokaryon at the onset of sporogony from the male host . . . . . 32

37 Electron micrograph of an early binucleate sporont from the male host.......... 34

38 Electron micrograph of a binucleate sporont from the male host............ 34

39 Electron micrograph of a meiotically dividing sporont from the male host.......... 34

40 Electron micrograph of a quadrinucleate sporont from the male host......... 34

41 Electron micrograph of young sporoblasts contained within a pansporoblast membrane from the male host........... 36

42 Electron micrograph of a mature sporoblast from the male host............ 36

43 Electron micrograph of a mature spore from the male host................ 36

44 Electron micrograph of a mature macrospore from the male host........... 36

45 Prevalence rate of infection for successive generations of a theoretical population of c. salinarius infected with Amblyospora sp. where the parasite is maintained by transovarial transmission alone. 
Abstract of Dissertation Presented to the Graduate Council of the University of Florida in Partial Fulfillment of the Requirements for the Degree of Doctor of Philosophy

\author{
LIFE CYCLE AND EPIDEMIOLOGY OF \\ Amblyos pora sp. (MICROSPORA: THELOHANIIDAE) \\ IN THE MOSQUITO CuleX salinarius COQUILLETT
}

By

Theodore George Andreadis

December 1978

Chairman: Donald W. Hall

Major Department: Entomology and Nema tology

Amblyospora sp. in Culex salinarius is transovarially transmitted and exhibits two developmental sequences, one in each host sex. In females, the entire life cycle is restricted to host oenocytes which become greatly hypertrophied due to the multiplication of diplokarya during merogony and come to lie next to the host ovaries. Sporogony occurs only after a blood meal is taken and is shortly followed by infection of the developing oocytes and subsequent transmission to the next host generation. In the male host, infections spread from oenocytes to fatbody tissue where diplokarya undergo a second merogony. During this merogonic cycle, the number of diplokarya greatly increase and the infection is spread throughout the body of the larval host. Sporogony is initiated with the physical separation of the diplokaryotic nuclei and the simultaneous secretion of a pansporoblastic membrane. Subsequent meiotic division and morphogenesis result in the formation 
of eight haploid spores enclosed within a pansporoblastic membrane. Buildup of spores and subsequent destruction of host fatbody tissue prove fatal to the male during the fourth larval stadium.

Adult females infected with the microsporidium showed no significant differences in overall fecundity, physiological longevity and preoviposition periods when compared to heal thy adults under laboratory conditions. Development times and survival rates for congenitally infected young to reproductive age were also indistinguishable from those of healthy controls. A significant reduction of $52 \%$ in egg hatch was observed for infected eggs when compared to healthy eggs. Prevalence rates of infection for progeny produced by infected females declined with each successive gonotrophic cycle and averaged $90 \%$. Transovarial transmission is not sufficient for the maintenance of the microsporidium in a population of mosquitoes. An alternate host is suggested as a mechanism whereby the microsporidium can re-enter a heal thy mosquito population. 


\section{INTRODUCTION}

The microsporidia are a large group of obligate, intracellular parasites which occur worldwide and exhibit a broad host range, infecting all phyla of the animal kingdom from protozoa to man (Bulnheim, 1975). However, they are most frequently encountered as parasites of arthropods and are important pathogens of many insect groups.

They are among the most common and widely distributed pathogens found infecting natural populations of mosquitoes, of ten causing severe diseases (Chapman, 1974). Hazard and Chapman (1977) list more than 100 mosquito species worldwide as known hosts of these parasites and it is likely that all mosquito species somewhere, sometime are hosts (Chap$\operatorname{man}, 1974)$.

Because of their wide distribution, common occurrence and apparent pathogenicity, microsporidia appear to be promising candidates for the biological control of many mosquito species. However, the life cycles and mode of transmission of many of these parasites are poorly understood. An elucidation of these mechanisms is vital to future research programs which seek to utilize these parasites for mosquito control.

This study was undertaken to determine the relationship between a microsporidian parasite, Amblyospora sp., and its natural mosquito host, Culex salinarius Coquillett. 
This dissertation consists of a literature review which provides information on the biology of mosquito microsporidia and two chapters containing all experimental work, written in manuscript form, which are currently being submitted for publication. 


\section{LITERATURE REVIEW}

\section{The Microsporidia}

Definition and taxonomic status

Microsporidia are obligatory intracellular parasites, incapable of development and multiplication outside of the host cell. They are characterized by the formation of unicellular spores equipped with an extrusible polar filament and the absence of mitochondria. Formerly considered a distinct class of protozoans they have most recently been elevated in rank to an independent phylum, the Microspora (Sprague, 1977).

\section{Structure}

All microsporidian cells, other than spores, are structurally simple and unspecialized. With the exception of the absence of mitochondria, their structural organization is typical of other eucaryotic cells (Vâvra, 1976a).

The microsporidian nucleus is typically round or oval and enclosed in a unit membrane, perforated with pores (Vávra, 1965). The outer membrane is studded with ribosomes and has continuities with the endoplasmic reticulum (Maurand, 1966). Many times the microsporidian nuclear component exists as two structurally identical nuclei in intimate association which behave in synchrony - the diplokaryon (Vávra, 1968).

The microsporidian cytoplasm has the usual organelles including both rough and smooth endoplasmic reticulum, free and bound ribosomes, 
golgi apparatus, and vesicles of endocytosis all enclosed in a cell limiting membrane (Vávra, 1965; Lom and Corliss, 1967; Sprague and Vernick, 1968, 1969; Vernick et al., 1977).

There are no reserve substances in microsporidian cells (Maurand and Loubes, 1973). Their absence, according to Vâvra (1976a) is in keeping with their obligatory, intracellular existence which excludes any metabolically active stage outside the host cell.

In contrast to its developmental stages, the microsporidian spore is a highly differentiated cell, specifically adapted to its function of transmitting infectious material to a new host.

It is endowed with a protective trilaminar envelope or wall consisting of a thin proteinaceous outer layer (exospore), a thick middle layer composed of chitin (endospore), and a thin cytoplasmic limiting membrane (Vávra, 1964, 1967, 1968).

Within this protective wall exist one or more nuclei and cytoplasm which constitute the sporoplasm or infective germ (Weidner, 1972) and a highly specialized extrusion apparatus consisting of three distinct parts (Lom and Vavra, 1963): (1) polar filament (tube) - a solid, tubular, threadlike structure of great elasticity attached to the inner surface of the spore and coiled within, which when extruded provides the vehicle through which the infective sporoplasm is ejected, (2) polaroplast - a laminar or vesicular complex which swells to provide the initial intrasporal pressure necessary for polar filament extrusion, and (3) posterior vacuole - a membrane limited vacuole capable of expansion providing the additional pressure necessary for further polar filament extrusion and ejection of the infective sporoplasm. 
General scheme of the life cycle

The typical microsporidian life cycle is initiated with the liberation from the spore of the sporoplasm which passes through an evaginated polar filament and enters a host cell (Lom and Vávra, 1963; Ishihara, 1968; Weidner, 1972).

The stimulus for spore filament extrusion and release of the infective sporoplasm in the host is complex and varied but most evidence indicates this process to be affected by $\mathrm{pH}$ and the presence of certain cations which cause an osmotic shift within the spore (Ohshima, 1964; Ishihara, 1967). Presumably, this results in an influx of water, producing a sudden buildup in hydrostatic pressure necessary for forcible extrusion of the filament (Weidner, 1976). Lom and Vâvra (1963) have shown polar filament discharge intensity to be directly proportional to the osmotic condition or the viscosity of the medium exterior to the spore.

Within the host cell, the microsporidium undergoes an initial multiplicative phase (merogony) during wiich the number of parasites rapidly increases and the infection is spread throughout the body of the host (Vavra, 1976b).

After merogony the parasites enter a second phase of development called sporulation. During sporulation additional multiplication by binary or multiple fission (sporogony) occurs followed by morphogenes is culminating in the formation of new spores capable of infecting new susceptible hosts (Vávra, 1976b).

This entire developmental sequence occurs intracellularly in a variety of tissue types dependent upon the host and the species of microsporidia. Insect tissues infected include fatbody, gut, muscle, 
nerve, gonads, salivary gland, malpighian tubules and oenocytes (Weiser, 1976).

To date all reproduction in microsporidia has been reported to be asexual. However, recent cytological evidence of meiotic divisions in certain species (Loubès et al., 1976; Vávra, 1976a; Hazard et al., 1978) suggests a sexual phase.

\section{Transmission}

Microsporidia are normally transmitted when spores from feces or cadavers of infected hosts are ingested by new hosts (Canning, 1971).

Transmission may also take place between hymenopterous parasites and their insect hosts, the spores being carried on the contaminated ovipositor (Brooks, 1973). In many cases the hymenopterous vector is infected by the same microsporidia as its host (Tanada, 1955; Lipa, 1957), although pure mechanical transmission, with no development of the microsporidia in the wasp, may also occur (Lipa, 1963; Laigo and Tamashiro, 1967).

The major route of transmission of microsporidian parasites in insects is through the mouth, but transmission by way of the ovary (transovarial) or surface of the egg (transovum) has also been shown to commonly occur in many insect groups (Kellen and Wills, 1962a; Kellen et al., 1965, 1966; Chapman et a1., 1966; Brooks, 1968; Hazard and Weiser, 1968; Chapman, 1974; Nordin, 1975). In mosquitoes, the former appears to be the principal, if not only, means of transmission of certain microsporidian genera (Kellen et al., 1965; Chapman et al., 1966) and in some cases has been considered sufficient to account for the low levels of infection observed in the field (Kellen et al., 1965, 1966; Chapman et a1., 1967). 
When entry occurs via the egg, infective stages are incorporated into the developing ova or embryos within the female reproductive tract and subsequently passed on to her progeny (Hazard and Weiser, 1968; Nordin, 1975).

Successful transmission of microsporidia to new hosts is dependent upon three primary factors (Weiser, 1969): (1) successful spore germination, (2) host tissue susceptability, and (3) active host resistance.

Effects of microsporidian infections on their insect hosts

The main characteristic of microsporidian infections is the chronic and debilitating effect they produce in their insect hosts. Often these effects are expressed by a general loss of vigor and disruption of vital physiological functions. However, infections may be expressed in a wide variety of ways ranging from complete host destruction to latency. Those effects, reported to date, can be categorized as follows.

1. No perceivable effect - Kellen et al. $(1965,1966)$ report that in certain genera of mosquitoes infected with Amblyospora spp., infected female larvae pupate normally and emerge as apparently heal thy adults which transmit the parasite transovarially.

2. Retarded development - Lengthening of the larval period is a common effect of microsporidian infections (Thompson, 1958; Gaugler and Brooks, 1975). In some cases microsporidia have been shown to produce a hormonal substance that results in supernumerary molts, slowing down or preventing pupation (Fisher and Sanborn, 1964).

3. Reduced longevity - Numerous studies have shown adult longevity to be significantly reduced for infected anophel ine mosquitoes 
(Anthony et al., 1972, 1978; Undeen and Alger, 1975) and many lepidopterous pests (Zimmack et al., 1954; Zimmack and Brindley, 1957; Kramer, 1959; Gaugler and Brooks, 1975; Windels et al., 1976).

4. Reduced reproductive potential - The principal effect of microsporidian infections is a reduction in the reproductive potential of the host. This is expressed by a reduction in overall fecundity (Veber and Jasic, 1961; Reynolds, 1971; Anthony et al., 1972, 1978; Gaugler and Brooks, 1975; Windels et al., 1976), egg hatch (Reynolds, 1971; Windels et al., 1976; Anthony et al., 1978), oviposition cycles (Anthony et al., 1972, 1978) or mating success (Gaugler and Brooks, 1975). Such effects, as suggested by Veber and Jasic (1961) and Thompson (1958), are probably the result of depleted nutritional reserves and reduced ability to assimilate food efficiently.

5. Impairment of diapause development - The initiation, maintenance, and termination of diapause in some lepidopterous pupae is affected by microsporidian infections (Issi and Maslennikova, 1964 ; Gaugler and Brooks, 1975). These effects may be due to a hormonal imbalance or nutritient reserve deficiency caused by microsporidian development (Gaugler and Brooks, 1975).

6. Death - Progressive multiplication of the parasite and subsequent destruction of host tissue may cause death (Weiser, 1976).

In general, the virulence and pathogenicity of microsporidian infections are dependent upon three primary factors (Weiser, 1963): (1) infective dose, (2) age of the host, and (3) tissues infected. Where peroral transmission occurs, the higher the dosage, the more acute and lethal is the infectious process. Young individuals are generally more susceptible to and succumb faster from infections than do older 
individuals. Microsporidia which infect the gut and musculature and those which are systemic produce more acute infections than those confined to fatbody tissue which are generally more chronic.

\section{Genus Amblyospora Hazard and 01dacre}

of the eleven genera of microsporidia known to infect mosquitoes, members belonging to the genus Amblyospora are by far the most common and widespread. To date, they have been reported from 47 species of mosquitoes representing 8 genera (Hazard and Chapman, 1977).

Most, if not all, species of Amblyospora are transovarially transmitted and exhibit two developmental sequences in their mosquito hosts: one in male or both male and female larvae, and another in adult females. Parasite development in larvae characteristically results in the production of eight thick-walled, oval, octospores enclosed in a pansporoblast membrane while that in adult females produces a variable number of thin-walled, cylindrical, free spores (Hazard and 0ldacre, 1975).

The relationship between many of these microsporidian parasites and their mosquito hosts has been categorized into four types based on the sex of the larva in which sporogony occurs and the tissues attacked (fatbody or oenocytes) (Kellen et a1., 1965; Chapman et al., 1966). In types I and II sporogony occurs in male larvae only producing massive infections which invariably prove fatal to the host during the fourth larval stadium. In females sporogony is delayed or suppressed. Female larvae pupate normally and emerge as apparently healthy adults which transmit the parasite transovarially when mated with heal thy males. In types III and IV sporogony occurs in larvae of both sexes but is 
progressive and usually fatal in type III only, those infections in type IV being relatively benign.

In types I and II, transovarial transmission is continuous for successive host generations and in some instances has been reported to be sufficient to account for the levels of infection observed in the field (Kellen et al., 1965, 1966; Chapman et al., 1967). Transovarial transmission may or may not be continuous in types III and IV. In some mosquitoes which develop infections characteristic of type III, transovarial transmission is limited to one generation (Kellen et al., 1966). In these mosquitoes, peroral transmission probably is the more common mode of transmission and would be expected for survival of the microsporidia (Kellen et al., 1966; Chapman et al., 1967).

While transovarial transmission of Amblyospora has been clearly demonstrated, peroral transmission has always been an enigma. Unlike many other microsporidia, spores produced in larvae do not appear to be infectious when fed directly back to their mosquito hosts. Successful transmission in the laboratory has been claimed only once (Kellen and Lipa, 1960). However, a succeeding report indicated that peroral transmission for the same microsporidia and mosquito host was not attainable (Kellen and Wills, 1962a). Subsequent attempts to transmit these microsporidia by rearing larvae in water contaminated with spores have also been unsuccessful (Kellen et al., 1965; Chapman, 1974).

Similar tests conducted under field conditions, by exposing larvae in screened containers in ponds with a past history of Amblyospora occurrence, have met with limited success, indicating that transmission may occur perorally when certain conditions are met (Kellen et al., 1966; Chapman et al., 1970). To date, what these conditions are has not been determined. 
DEVELOPMENT, ULTRASTRUCTURE AND MODE OF TRANSMISSION

DF Amblyospora sp. (MICROSPORA: THELOHANIIDAE) IN THE MOSQUITO CuleX sal inarius COQUILLETT

\section{Abstract}

Amblyospora sp. in Culex salinarius is transovarially transmitted and exhibits two developmental sequences, one in each host sex. In females, the entire life cycle is restricted to host oenocytes which become greatly hypertrophied due to the multiplication of diplokarya during merogony and come to 1 ie next to the host ovaries. Sporogony occurs only after a blood meal is taken and is shortly followed by infection of the developing oocytes and subsequent transmission to the next host generation. In the male host, infections spread from oenocytes to fatbody tissue where diplokarya undergo a second merogony. During this merogonic cycle, the number of diplokarya greatly increase and the infection is spread throughout the body of the larval host. Sporogony is initiated with the physical separation at the diplokaryotic nuclei and the simultaneous secretion of a pansporoblastic membrane. Subsequent meiotic division and morphogenesis result in the formation of eight haploid spores enclosed within a pansporoblastic membrane. Buildup of spores and subsequent destruction of host fatbody tissue prove fatal to the male host during the fourth larval stadium.

\section{Introduction}

Microsporidia of the genus Amblyospora Hazard and 0ldacre are among the most common and widely distributed pathogens found infecting natural populations of mosquitoes. To date, they have been reported 
from 47 mosquito species representing 8 genera (Hazard and Chapman, 1977).

Most, if not all, species of Amblyospora are transovarially transmitted by their mosquito hosts and typically exhibit two developmental sequences, one usually, but not exclusively, in each host sex. In males, parasite development is rapid. Sporogony (formation of spores) occurs in larvae, producing massive infections which prove fatal to the host during the fourth larval stadium. In females, however, sporogony is delayed and limited to the oenocytes. Female larvae pupate normally and emerge as apparently healthy adults which transmit the parasite transovarially to their progeny when mated with heal thy males (Kellen et a1., 1965; Hazard and 01dacre, 1975).

Because of their wide distribution, common occurrence and apparent pathogenicity, these microsporidia appear to be promising candidates for the biological control of certain mosquito species. However, the manner in which these parasites develop in and are transmitted to their mosquito hosts has never been completely understood thus restricting their use.

A similar host-parasite relationship has been reported for an undescribed species of Amblyospora and its natural mosquito host, Culex salinarius Coquillett (Chapman et al., 1966). This study was undertaken to describe the complete development and ultrastructure of this microsporidium and to elucidate the mechanisms involved in transovarial transmission of the parasite to its mosquito host.

Because of the morphological similarities of this Amblyospora sp. from $\underline{C}$. Salinarius to that of Amblyospora californica Kellen and Wills, taxonomic description of the former species was delayed until a complete life cycle study of the latter species could also be made. 


\section{Materials and Methods}

Experimental animals

The healthy and Amblyospora sp.-infected colonies of $\underline{C}$. Salinarius used in this study were originally obtained from Dr. Harold Chapman, Gulf Coast Mosquito Research Laboratory, Lake Charles, Louisiana. Adults were maintained in $38 \times 46 \times 38 \mathrm{~cm}$ cages at $24 \mathrm{C}$ under natural photoperiod and were constantly supplied with a $5 \%$ sucrose solution in distilled water. Since almost all males from the infected colony died during the fourth larval stadium, males from the heal thy colony were used to inseminate infected females.

Females were fed on guinea pigs placed directly into the cage. Egg rafts infected with the microsporidia were deposited into half-pint containers and individually transferred into white enamel pans (18x29x $4.5 \mathrm{~cm}$ ) containing $500 \mathrm{ml}$ of well water for larval rearing. Rearing was at $25 \mathrm{C}$. The water was infused with $10 \mathrm{ml}$ of an aqueous suspension containing $1.5 \%$ of a $3: 2$ mixture of dried liver powder and brewers yeast. Larvae were fed on alternate days until all had pupated or died. Simultaneous maintenance of the heal thy colony was performed in a similar manner.

\section{Life cycle studies}

To determine the developmental sequences and complete life cycle of the parasite, all stages of both sexes of the mosquito host were chronologically examined for the microsporidia.

General characterization of the microsporidian stages at the light microscope level was made from giemsa-stained smears of infected host tissues as described by Hazard and 01dacre (1975). Sites of infection within the mosquito host were determined from whole mosquitoes 
fixed in Carnoy's solution, embedded in paraffin, sectioned at $6 \mu \mathrm{m}$ and stained with Heidenhains hematoxyl in and Eosin $y$.

For 41 trastructural studies, infected specimens were dissected in $2.5 \%$ gluteraldehyde buffered with $0.1 \mathrm{M}$ sodium cacodylate ( $\mathrm{pH} 7.5)$ and fixed for $2 \mathrm{hr}$ at room temperature, in the dark in $2.5 \%$ gluteraldehyde, $0.1 \%$ peroxide in $0.1 \mathrm{M}$ cacodylate buffer, pH 7.5 (Peracchia and Mittler, 1972). After several buffer washes, specimens were post fixed in $1 \%$ osmium tetroxide, dehydrated in an ethanol series, en bloc stained with $0.5 \%$ uranyl acetate in $70 \%$ ethanol and embedded in either Spurrs (Spurrs, 1969), a Spurr-Epon mixture (E11 is and Avery, 1978), or EponAraldite. Sections were poststained with $5 \%$ methanolic uranyl acetate, followed by lead citrate (Reynolds, 1963) and viewed with a Hitachi HU-125 E electron microscope at an acceleration voltage of $75 \mathrm{kV}$.

In addition to eggs, larvae and pupae, adult females of different physiological age, ranging from recently emerged to fully gravid, were examined at the light microsope and ultrastructural level to determine the mechanism by which the microsporidia infected the ovaries and were subsequently transmitted to the next generation.

\section{Results}

The complete developmental sequence of Amblyospora sp. in both sexes of the mosquito host, $\underline{C}$. salinarius, is shown in Figure 1.

Infections are initiated when small binucleate sporoplasms (Figs. $1 a, 25)$ infect the developing eggs within the female host and are subsequently transferred to the next generation when the eggs are laid. Within embryonated eggs and newly hatched larvae of both sexes small, oval, diplokaryotic stages (Figs. Ib, 2) invade host oenocytes and undergo an initial multiplicative phase (merogony) where they divide mitotically to produce more diplokarya (Figs. Ib-d, 2-4). 
In the female host, initial parasite development within these oenocytes is slow and infections relatively benign. Infected larvae develop normally, pupate and emerge as apparently healthy adults. However, at adult emergence the parasites enlarge, become fusiform in shape (Figs. 5, 6, 27) and enter a second merogonial phase of development where they now begin to rapidly divide within the same oenocytes which become greatly hypertrophied due to the multiplication of the parasite (Figs. 1e-h, 5-8, 26-27).

Infected oenocytes circulate or actively migrate through the hemocoel of the female host until they come to reside in very close proximity and in many cases lie next to the host ovaries (Fig. 23). Within these oenocytes, the microsporidia remain in the diplokaryotic stage until a blood meal is taken by the female host at which time they begin sporogony (Figs. $1 i-j$ ). During this final phase of development, which requires 40-48 hrs to complete, the diplokarya undergo a tremendous amount of internal reorganization and develop directly into binucleate spores (Figs. 28-29). Mature spores are elongate and characterized by having a relatively thin wall and a large conspicuous posterior vacuole (Figs. 10,30).

Spores, still contained within host oenocytes (Fig. 24), are short lived and within a 12-24 hr period begin to evert their polar filaments and forcibly discharge their amoeboid-shaped sporoplasms into the surrounding hemocoel (Fig. 31). These binucleate sporoplasms (Fig. 25) subsequently infect the developing oocytes and thus complete the cycle when the eggs are laid. Sporulation in other oenocytes and ovarian infection are repeated during each successive gonotrophic cycle of the host. 
In the male host, the developmental sequence of the parasite resembles that in the female during the initial stages of development but then quickly diverges. Infections begin in the embryonated egg where the microsporidium initially invades host oenocytes and rapidly multiplies to produce numerous diplokarya during merogony (Figs. 1b-d, 2-4, 32). However, unlike female infections which are confined to the host oenocytes, the diplokarya in the male host break out of the oenocytes and invade thoracic and abdominal adipose tissue of late first and early second instar larvae (Fig. 33). Here they enter a second multiplicative phase (merogony 2) during which the number of diplokarya greatly increase and the infection is spread throughout the body of the larval host (Figs. 1f-h, 11-14, 34).

After this merogonic multiplication, the parasite enters its last phase of development, sporogony, where additional division and morphogenesis result in the formation of spores in groups of eight (Figs. $(n-r)$. The process begins with separation of the diplokaryotic nuclei and the simultaneous secretion of a pansporoblastic membrane (Figs. 35-37) to form a binucleate sporont (Figs. 15, 38). The two nuclei of the sporont divide synchronously (Fig. 39) to produce a quadrinucleate stage (Figs. 16, 40) which divides again (Fig. 17) before undergoing cytokinesis to form eight sporoblasts, all still contained within the pansporoblastic membrane (Figs. 18-19, 41-42). Also within this membrane are numerous metabolic products (granules) secreted by the developing sporonts and readily observed at the ultrastructural level (Figs. 37-41). The repeated occurrence of synaptonemal complexes in binucleate sporonts (Fig. 38) indicates this division process to be meiotic and the resulting sporoblasts haploid. 
Each of the eight sporoblasts develops directly into a uninucleate spore characterized by the possession of a thick exospore wall, a conspicuously lamellated polaroplast, and a long polar filament abruptly constricted near its middle (Figs. 20, 43). Occasionally spores almost double in size (macrospores) are observed, which with the exception of their size appear structurally identical at the ultrastructural level to normal sized spores (Fig. 21, 44). Presumably, they arise from the incomplete division of one or more of the nuclei contained in quadrinucleate sporonts. They are however, still haploid, having completed the first meiotic division.

The massive buildup of spores and subsequent destruction of host fatbody tissue (Fig. 22) usually prove fatal to the male host during the fourth larval stadium. Occasionally a few individuals pupate and emerge as adults but always die within a $24-h r$ period. Dissections of these adults has always revealed mature spores but in relatively low numbers.

\section{Discussion}

The development of this species of Amblyospora in the mosquito C. salinarius is clearly dimorphic, exhibiting two complete developmental sequences: one fatal in males, producing spores in groups of eight enclosed by a pansporoblastic membrane, and another in females, producing a variable number of free spores which infect the ovaries and ensure passage to the next host generation.

Similarities between the two sequences are exhibited only during the initial phase of development where diplokarya invade oenocytes and undergo merogony within the embryonated eggs and newly hatched larvae. 
As early as late first instar larvae, however, differences in parasite development can be observed.

In the female host, the entire life cycle is restricted to host oenocytes which become greatly hypertrophied due to the multiplication of diplokarya by the time of adult emergence. Infected oenocytes, readily observed throughout the thorax and abdomen at this time, subsequently circulate or actively migrate through the hemocoel of the female host until they come to lie next to the developing eggs. Sporogony is initiated only after a blood meal is taken by the female host and requires 40-48 $\mathrm{hr}$ to complete. The repeated observation that spore maturation will not occur until a blood meal is taken by the female host regardless of her age, clearly demonstrates the close relationship between the biology of the microsporidian parasite and the physiology of the mosquito host. While the physiological mechanism for sporulation is not known at this time, the involvement of host hormones, shown to be released with a blood meal (Hagedorn, 1974; Hagedorn et al., 1975) should be investigated.

Mature spores are short 1 ived and within a 12-24 $\mathrm{hr}$ period begin to extrude their sporoplasms within the oenocytes. The exact mechanism by which these sporoplasms infect the ovaries is not understood. Sporoplasms may actively invade the ovaries or they may be nonselectively taken up by the developing oocytes which are sequestering vitellogenins by pinocytosis (Roth and Porter, 1964).

Sporulation in other oenocytes and subsequent ovarian infection are repeated during each successive gonotrophic cycle. Thus by this unique method, the microsporidium appears to ensure its survival in a continually breeding population of host mosquitoes. 
In the male host, initial parasite development is also restricted to oenocytes but is much more rapid and prolific than that occurring in the female host. Diplokarya subsequently break out of oenocytes and invade host fatbody cells where they multiply repeatedly. This second merogony sequence provides the primary instrument by which the parasites increase in number. It appears these diplokarya are capable of invading additional fatbody cells because it is during this phase of development that infections are spread throughout the body of the larval host.

The end of merogony and the onset of sporogony are characterized by the physical separation of the diplokaryotic nuclei and the simultaneous secretion of a pansporoblastic membrane. The observation that the nuclei of the diplokaryon simply separate during this phase of development is unquestionably confirmed at the ultrastructural level and provides further evidence that no karyogamy of diplokaryotic nuclei exists as has been suggested by previous investigators (Mercier, 1909; Kudo, 1924; Debaisieux, 1928; Heiser, 1977). Furthermore, no evidence exists for the presence of either uninucleate sporonts or meronts as have been described for other species of Amblyospora with similar developmental sequences (Kellen and Lipa, 1960; Kellen and Wills, 1962b; Anderson, 1968). Based on these findings, I now suspect that uninucleate meronts described by these investigators for Amblyospora spp. at the light microscope level are in fact diplokaryotic and can only be resolved at the ultrastructural level.

The repeated observation of synaptonemal complexes in binucleate sporonts indicates the division process during sporogony to be meiotic and the resulting spores to be haploid. These findings support the work of Loubès et al. (1976) and Vávra (1976a) who observed similar 
ultrastructural evidence for meiosis in Gurleya chironomi and Tuzetia debaisieuxi, respectively. Verification of these ultrastructural findings in the same species of Amblyospora has recently come from Hazard et a1. (1978) who documented meiosis through the examination of chromosome squashes.

The significance of these events in the life cycle of this microsporidium are unclear. All attempts to transmit this parasite by the direct feeding of haploid spores to heal thy mosquito larvae have been unsuccessful both in our lab and by previous investigators (Kellen and Wills, 1962a; Kellen et al., 1966). However, from an evolutionary standpoint it is hard to rationalize an organism putting that much energy into the production of spores that have no function and are produced by the millions within male larvae of each host generation. Therefore, our observations confirm the contention of Hazard et a1. (1978) that a sexual process involving these haploid spores may be completed in an alternate host. 
Fig. 1. Life cycle of Amblyospora sp. in C. salinarius. (a) Binucleate sporoplasm, (b-d) primary diplokaryon and stages of the lst merogony in oenocytes of embryonated eggs and young larvae, (e) transitional diplokaryon, $(f-h)$ secondary diplokaryon and stages of the 2nd merogony in oenocytes of newly emerged adult females, (i) sporoblast, (j) mature spore, $(k-m)$ secondary diplokaryon and stages of the 2 nd merogony in adipose tissue of young male larvae, $(n)$ binucleate sporont, (o) quadrinucleate sporont, ( $p$ ) octonucleate sporont, (q) pansporoblast containing eight sporoblasts, $(r)$ mature haploid spore. 


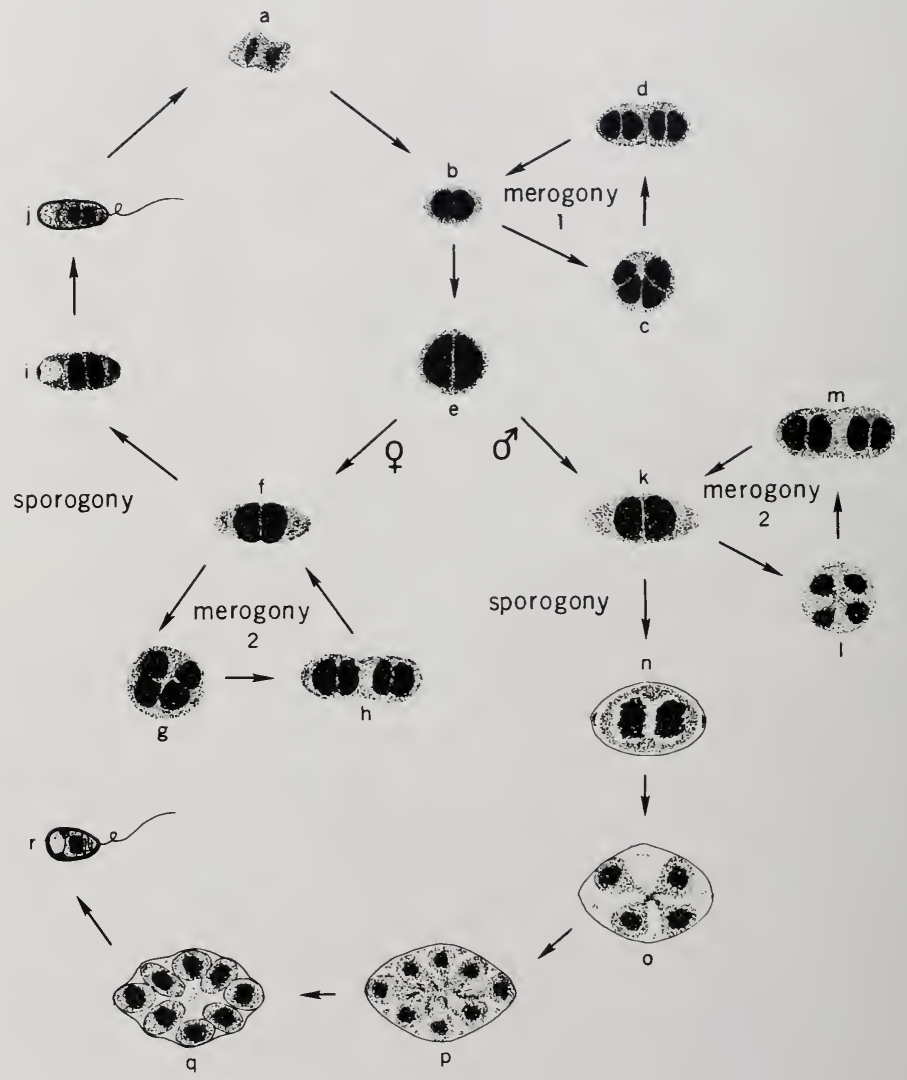


Figs. 2-21. Photomicrographs of giemsa stained and living material of Amblyospora sp.; $(6-10)$, stages in the female host; (11-12), stages in the male host. $\times 1,000$.

Fig. 2. Primary diplokaryon.

Fig. 3. Dividing diplokaryon.

Fig. 4. Dividing diplokaryon.

Fig. 5. Intermediate diplokaryon.

Fig. 6. Secondary diplokaryon.

Fig. 7. Dividing diplokaryon.

Fig. 8. Divided diplokarya.

Fig. 9. Sporoblast.

Fig. 10. Mature spore, Nomarski phase.

Fig. 11. Secondary diplokaryon.

Fig. 12. Dividing diplokaryon.

Fig. 13. Dividing diplokaryon.

Fig. 14. Dividing diplokaryon.

Fig. 15. Binucleate sporont.

Fig. 16. Quadinucleate sporont.

Fig. 17. Octonucleate sporont.

Fig. 18. Pansporoblast with eight sporoblasts.

Fig. 19. Spores in pansporoblast membrane.

Fig. 20. Mature spores, Nomarski phase.

Fig. 21. Macrospores, Nomarski phase. 


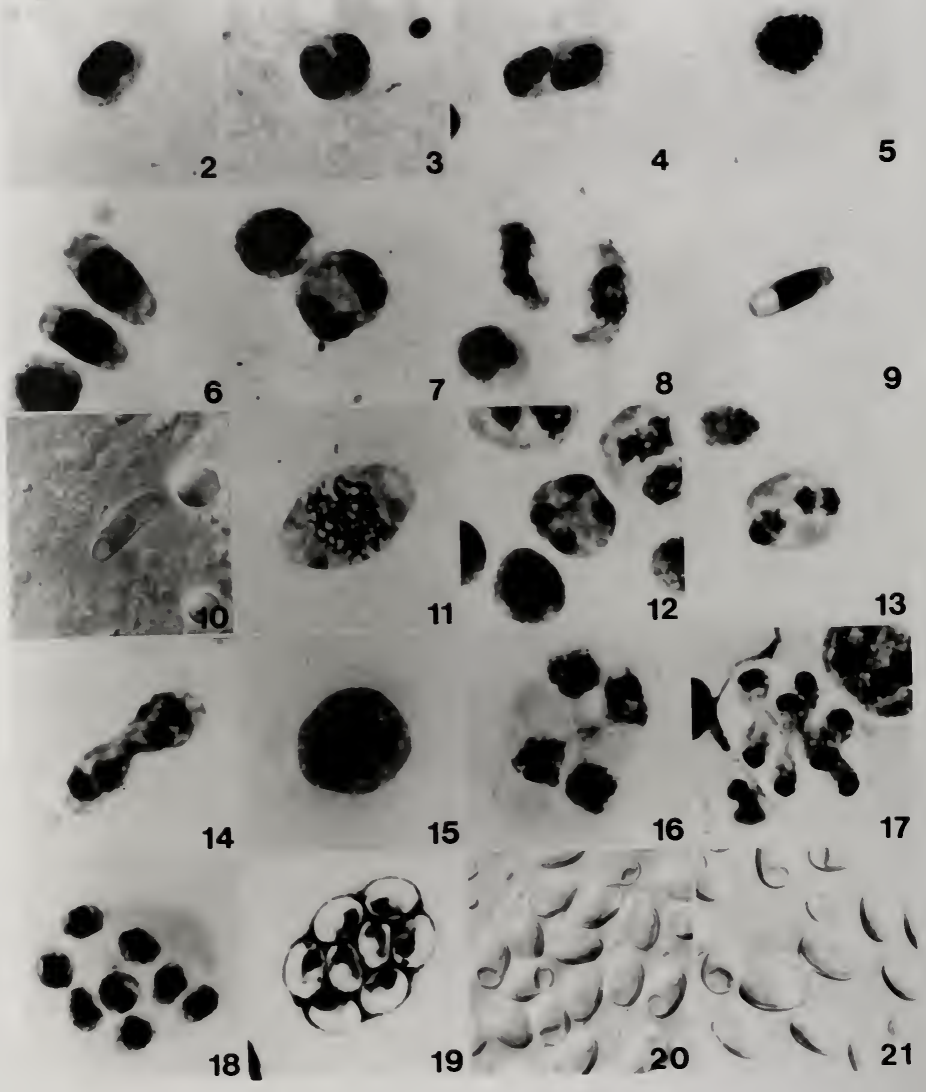


Fig. 22. Sagittal section through the thorax and first few abdominal segments of a fourth instar male larva of $\underline{C}$. salinarius infected with Amblyospora sp. $\times 60$.

Fig. 23. Amblyospora sp.-infected oenocyte containing numerous diplokarya lying next to the ovaries of a newly emerged adult female $C$. salinarius. X 390 .

Fig. 24. Amblyospora sp.-infected oenocyte containing mature spores in close association with the developing oocytes of an adult $C$. Salinariu female $48 \mathrm{hr}$ after a blood meal. X 340 .

Abbreviations: Fb, uninfected fatbody; I, infected fatbody; 0e, infected host oenocyte; 00 , host oocyte; Ov, host ovary; $\mathrm{S}$, mature spore. 

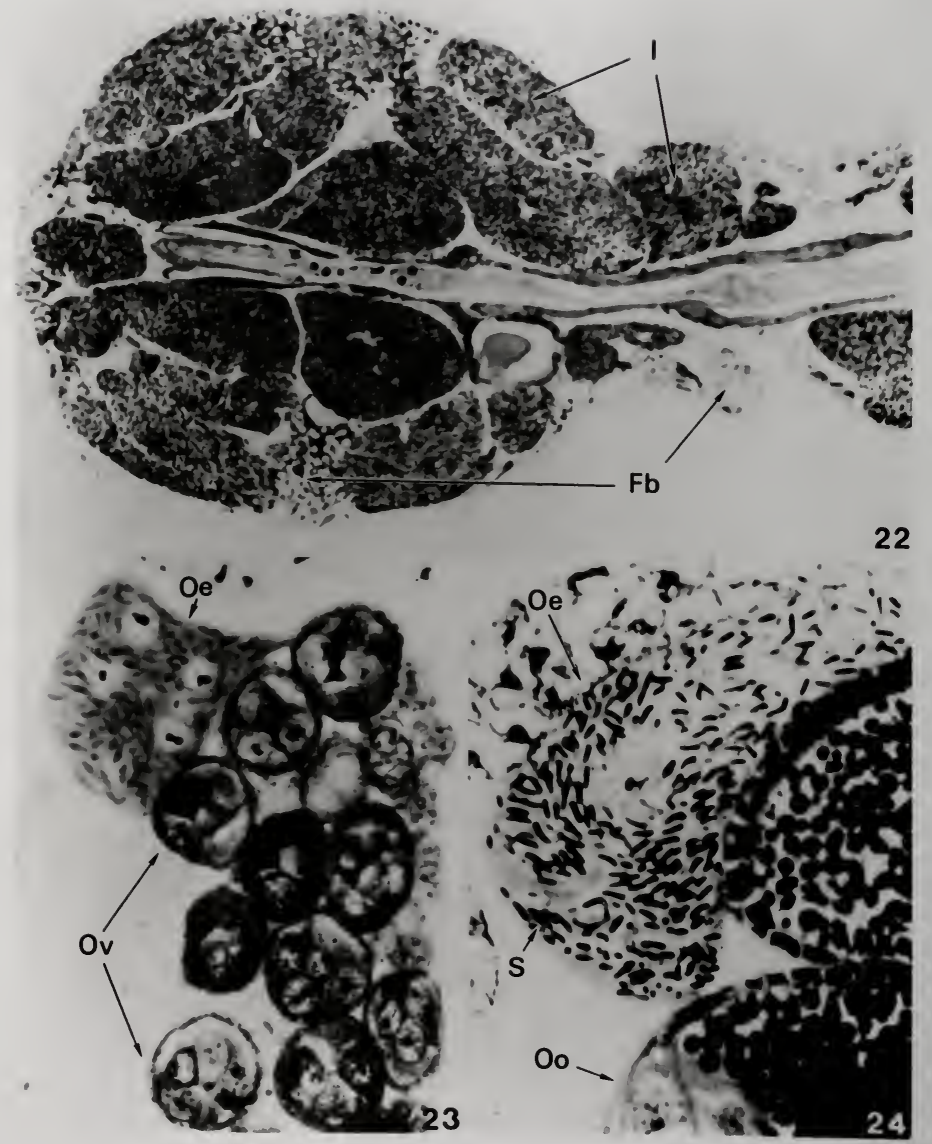
Figs. 25-44. Electron micrographs of the developmental stages of Amblyospora sp. in C. salinarius; (25-31 stages in the female host; $(32-44)$ stages in the male host.

Abbreviations: CM, cytoplasmic membrane; $D$, diplokaryon; $E N$, endospore wal1; EX, exospore wall; MG, metabolic granules; $N, N_{1}-$ $\mathrm{N}_{5}=$ microsporidium nucleus $(i)$; $N f b$, host fatbody nucleus; NM, nuclear membrane; No, host oenocyte nucleus; P, polaroplast; PC, polar cap; PF, polar filament; PM, pansporoblastic membrane; PV posterior vacuole; RER, rough endoplasmic reticulum; Sb, sporoblast; SC, synaptonemal complex; SW, spore wall.

Fig. 25. Recently extruded binucleate sporoplasm observed in the hemocoel of an adult female $60 \mathrm{hr}$ following a blood meal. $x 10,700$.

Fig. 26. Heavily infected oenocyte from a recently emerged adult female containing numerous secondary diplokarya (D) in cross and longitudinal section. $\times 4,100$.

Fig. 27. Enlarged, fusiform, secondary diplokaryon. Note the arrangement of the two nuclei $\left(\mathrm{N}_{1}\right.$ and $\left.\mathrm{N}_{2}\right) . \times 6,900$.

Fig. 28. Young sporoblast with developing polaroplast $(P)$ and polar filament (PF) from an adult female $42 \mathrm{hr}$ following a blood meal. Note the arrangement of the nuclei which remain in the diplokaryotic state. $\times 8,800$. 

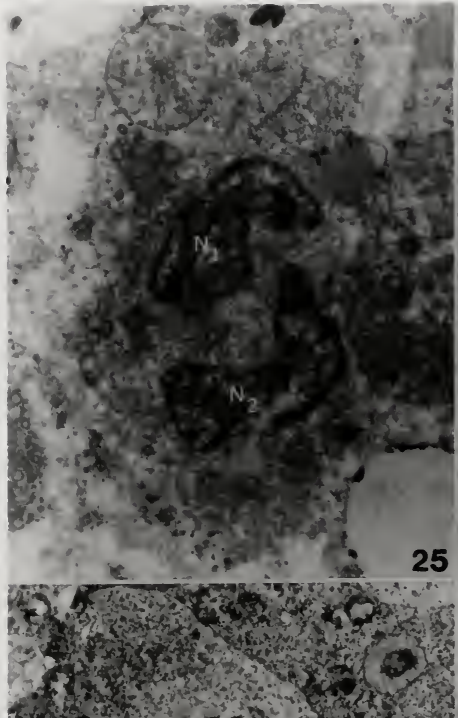

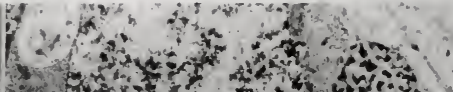

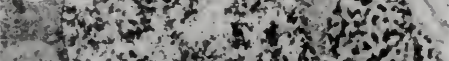

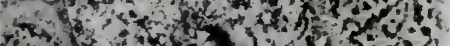

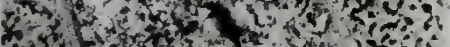

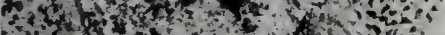

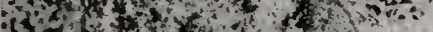

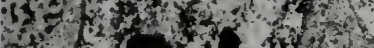

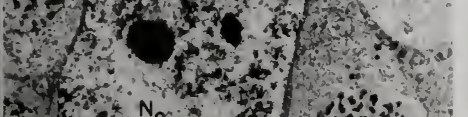

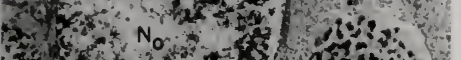

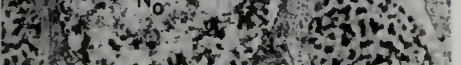

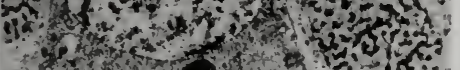
the $b^{2}$,

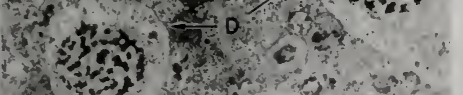
(3)

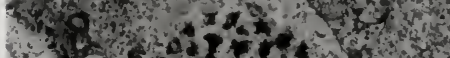

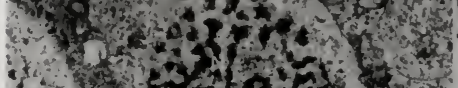

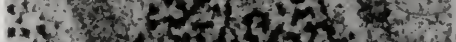

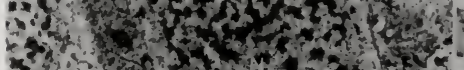
P.

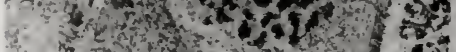

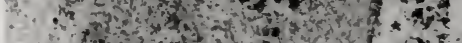

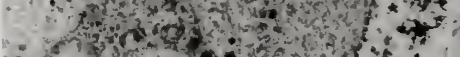

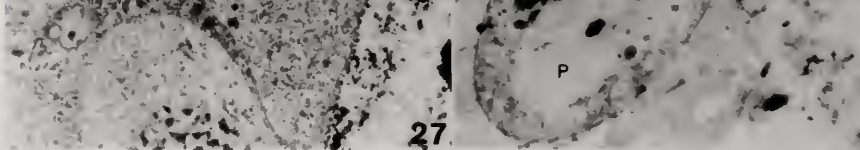
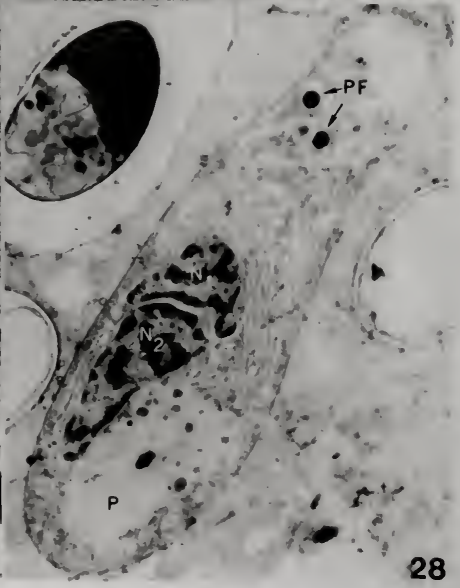
Fig. 29. Mature sporoblast from an adult female $44 \mathrm{hr}$ following a blood meal. Note the large conspicuous posterior vacuole (PV), relatively thin spore wall (SW) and the uniform thickness of the polar filament (PF). X 14,900 .

Fig. 30. Fully mature spore from an adult female $48 \mathrm{hr}$ following a blood meal. Note the attachment of the polar filament (PF) to the inner surface of the spore wall (SW) in the polar cap (PC) region. $\times 17,100$.

Fig. 31. Mature spore in the process of forcibly discharging its sporoplasm through the everted polar filament (PF). From an adult female $60 \mathrm{hr}$ following a blood meal. $\times 10,000$.

Fig. 32. Heavily infected oenocyte from a first instar male larva containing numerous primary diplokarya $($ D). $\times 4,000$. 


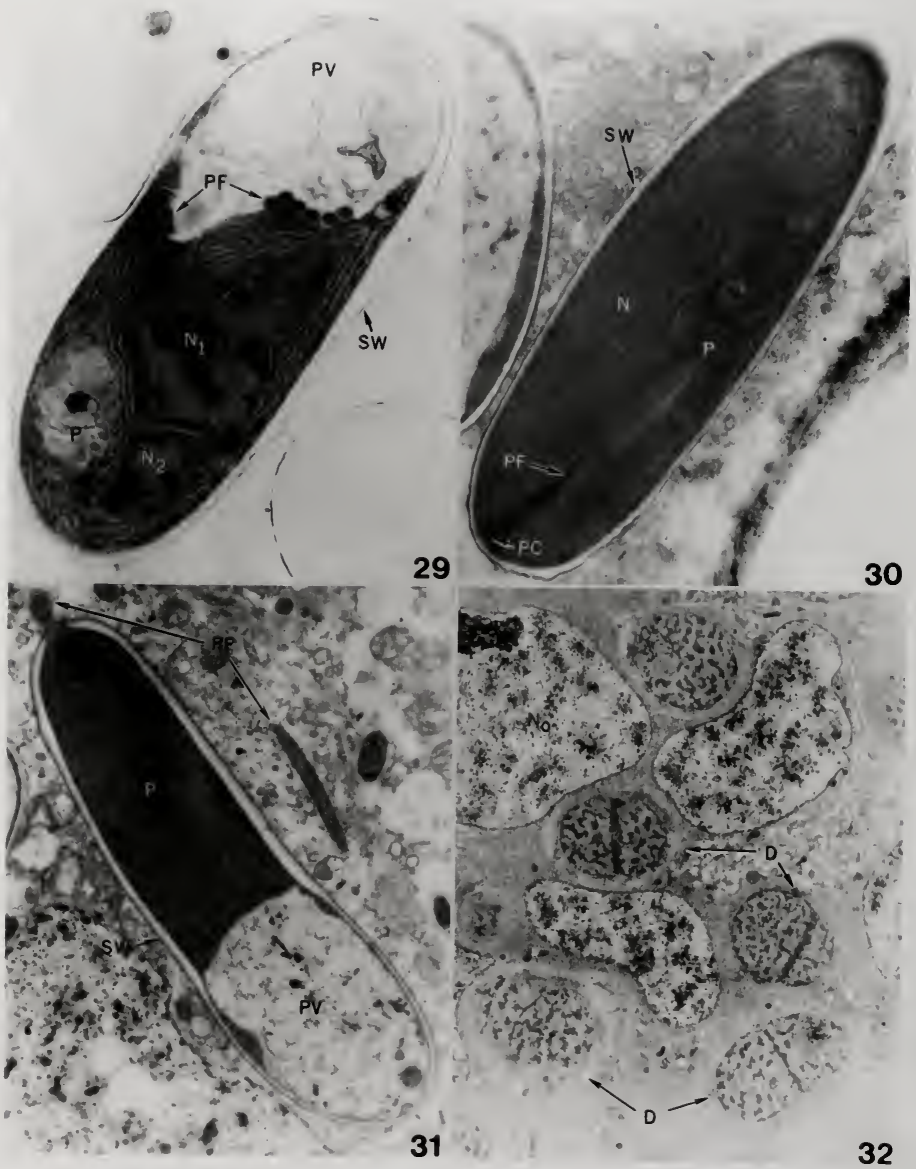


Fig. 33. Isolated diplokaryon (D) within the cytoplasm of an individual fatbody cell of a late first instar male larva. X 4,800.

Fig. 34. Diplokaryon in the state of mitotic division. Note the simultaneous dividion of the nuclei $\left(\mathrm{N}_{1}\right.$ and $\left.\mathrm{N}_{2}\right) . \times 5,700$.

Fig. 35. Secondary diplokaryon showing the distinct separation of the two nuclei ( $\mathrm{N}_{1}$ and $\mathrm{N}_{2}$ ). $\times 8,100$.

Fig. 36. Diplokaryon at the onset of sporogony. Note the physical separation of the nuclear membranes (NM) (arrow and insert) and the beginnings of the panosporoblastic membrane (PM). $\times 7,400$. Insert X 18,000 . 


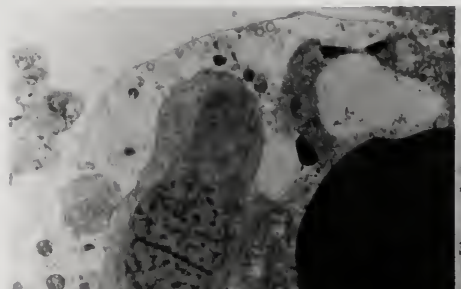

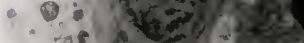

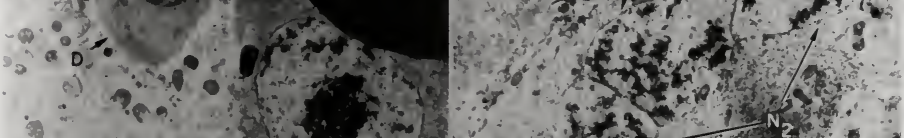
(8)

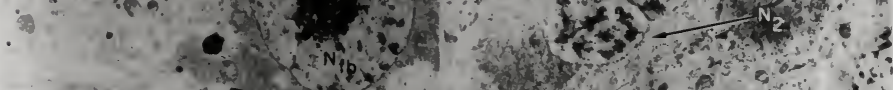
- $0_{33}$

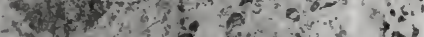

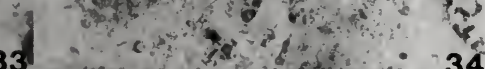

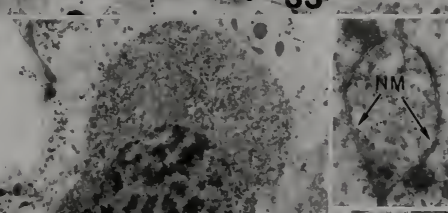

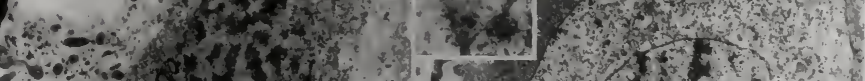

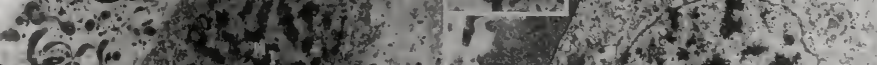

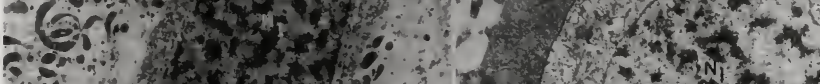

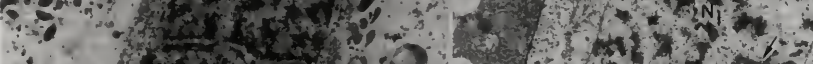

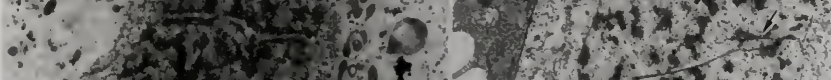

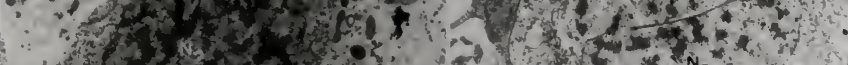

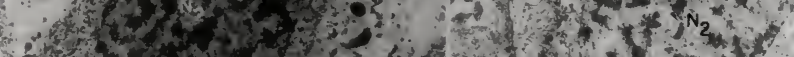

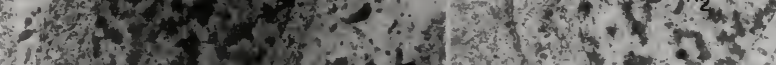

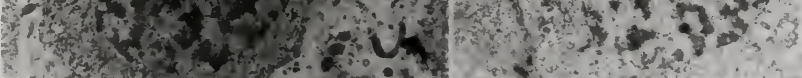

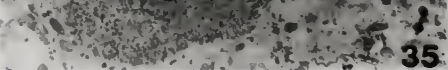

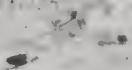


Fig. 37. Early binucleate sporont. Note the metabolic granules (MG) released by the microsporidium which collect within the pansporoblastic membrane (PM). X 7,000.

Fig. 38. Binucleate sporont. Note synaptonemal complex (SC) within the nucleus and the concentric stacks of rough endoplasmic reticulum (RER). $\quad \times 4,500$.

Fig. 39. Meiotically dividing sporont. $\times 7,200$.

Fig. 40. Quadrinucleate sporont showing three of the four nuclei ( $\mathrm{N}_{1}$ $\left.\mathrm{N}_{3}\right) . \times 7,400$. 


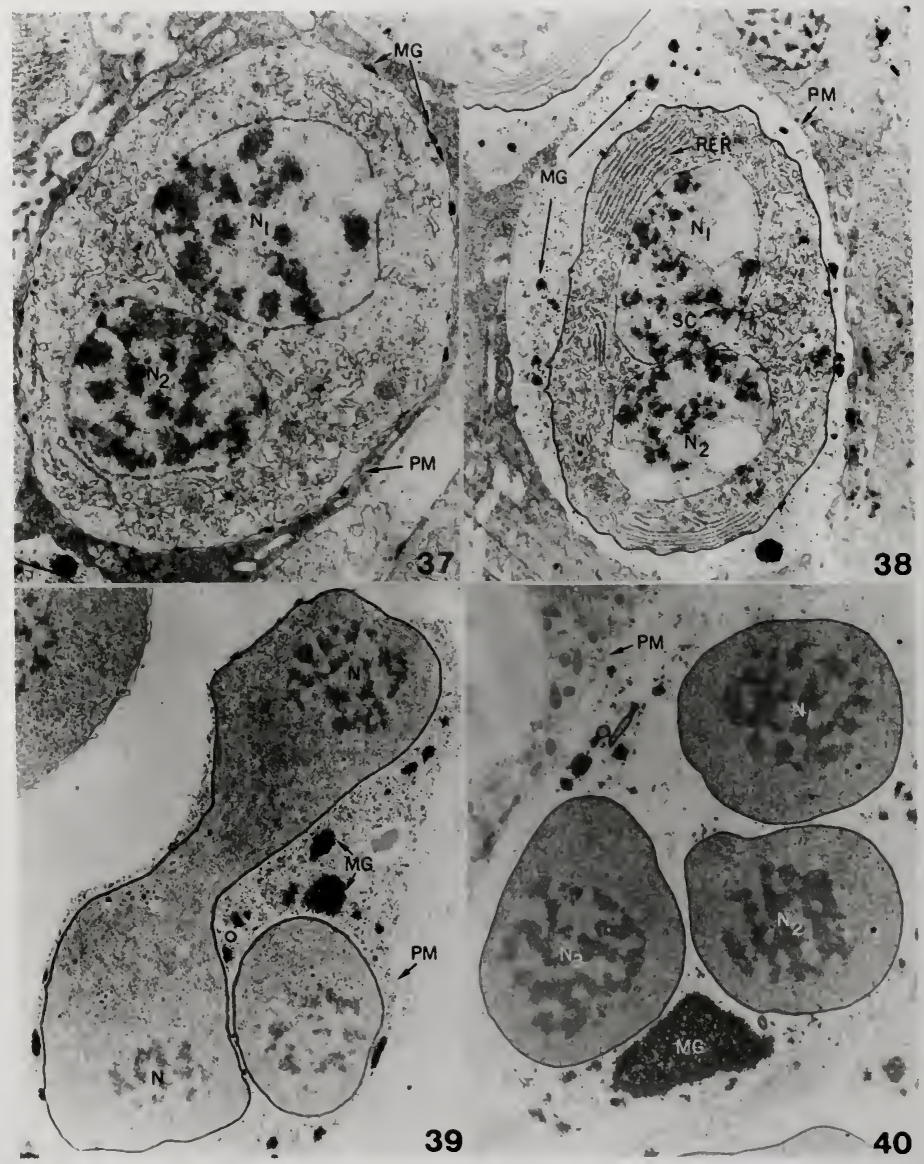


Fig. 41. Young sporoblasts (Sb) contained within a pansporoblastic membrane (PM). X 4,400.

Fig. 42. Mature sporoblast or immature spore showing the developing polar filament OPF) and spore wall (SW). X 14,500.

Fig. 43. Fully mature spore. Note the thick exospore wall (EX), conspicuously lamellated polaroplast (P), single nucleus $(N)$ and abruptly constricted polar filament (PF). X 14,800.

Fig. 44. Mature macrospore. Note its similarities to the normal-sized spore (Fig. 43) as well as the additional coils in the polar filament (PF) indicative of its increased size. Because of its U-shaped nature, the nucleus appears double in this section, but is, in fact, single. $\times 11,300$. 

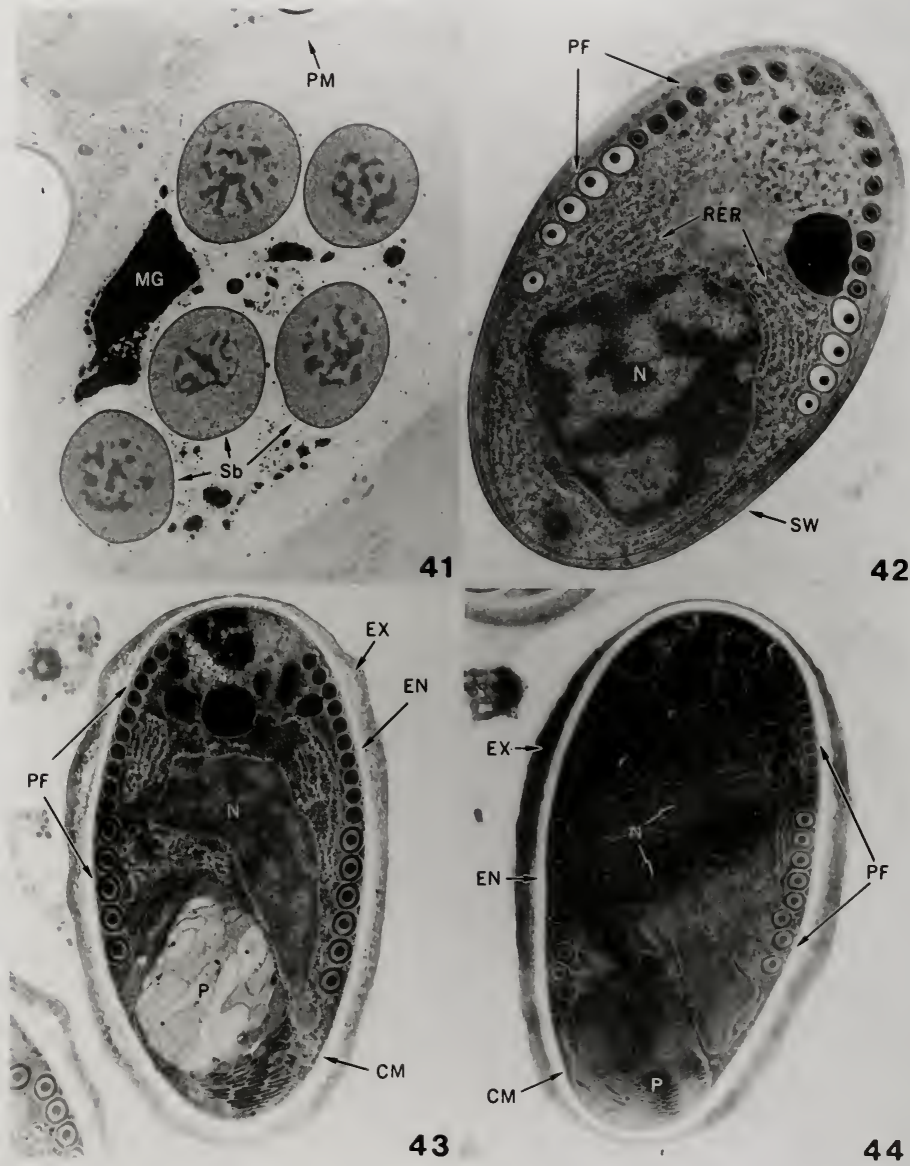
SIGNIFICANCE OF TRANSOVARIAL INFECTIONS OF

Ambl yospora sp. (MICROSPORA: THELOHANI IDAE)

IN RELATION TO PARASITE MAINTENANCE IN THE

MOSQUITO Culex sal inarius COQUILLETT

\section{Abstract}

Adult females of Culex salinarius, transovarially infected with the microsporidian Amblyospora sp. showed no significant differences in overall fecundity, physiological longevity and preoviposition periods when compared to heal thy adults under laboratory conditions. Development times and survival rates for congenitally infected young to reproductive age were also indistinguishable from those of heal thy controls. A significant reduction of $52 \%$ in egg hatch was observed for infected eggs when compared to healthy eggs. Prevalence rates of infection for progeny produced by infected females declined with each successive gonotrophic cycle and averaged $90 \%$. Transovarial transmission is not sufficient for the maintenance of the microsporidium in a population of mosquitoes. An alternate host is suggested as a mechanism whereby the microsporidium can re-enter a healthy mosquito population.

\section{Introduction}

Transovarial transmission of microsporidian parasites in mosquitoes is a well-known and widespread phenomenon (Kellen and Wills, 1962a; Kellen et al., 1965, 1966; Chapman et al., 1966; Hazard and Weiser, 1968; Chapman, 1974). In certain microsporidian genera it appears to be the principal, if not only, means of transmission (Kellen et al., 1965; Chapman et al., 1966). 
The expression of this host-parasite relationship is typically exemplified by an undescribed Amblyospora sp. and its natural mosquito host, Culex salinarius Coquillett. These microsporidians exhibit two developmental sequences, one in each host sex. In males, parasite development occurs in larvae producing massive infections which usually prove fatal to the host during the fourth larval stadium. In females, parasite development is suppressed or delayed and restricted to the oenocytes. Female larvae pupate normally and emerge as apparently healthy adults which transmit the parasite transovarially to their progeny when mated with healthy males (Kellen et al., 1965; Chapman et al., 1966).

Kellen et al. $(1965,1966)$ reported that in host-parasite relationships of this type, female fecundity was normal and concluded that transovarial transmission was sufficient to account for the levels of infection observed in the field. However, they presented no quantitative data comparing the reproductive potential of infected to healthy females. Surprisingly, very few studies have been conducted to demonstrate the sublethal effects of transovarially transmitted infections on their hosts. Gaubler and Brooks (1975) showed that in the corn earworm Heliothis zea, transovarial infections with Nosema heliothidis result in significant reductions in adult longevity and mating success thus reducing overall reproductive potential. On the other hand, Krinsky (1977) stated that transovarial infections of Nosema parkeri in the tick Ornithodoros parkeri do not appear to adversely affect host development or reproduction. Although several quantitative reports (Reynolds, 1970, 1971; Anthony et al., 1972, 1978; Undeen and Alger, 1975) have shown reduced physiological longevity, fecundity and egg hatch for 
anophel ine and culicine mosquitoes perorally infected with Nosema algerae and Pleistophora culicis, no such reports exist for transovarially induced microsporidian infections in mosquitoes.

This study was undertaken to determine the sublethal effects of Amblyospora $\mathrm{sp}$. on the reproductive potential and physiology of $\underline{\mathrm{C}}$. salinarius and to assess quantitatively the contribution of transovarial transmission to the maintenance of the infectious agent in a continuously breeding population of mosquitoes.

\section{Materials and Methods}

The healthy and Amblyospora sp.-infected colonies of $\underline{C}$. salinarius used in this study were originally obtained from Dr. Harold Chapman, Gulf Coast Mosquito Research Laboratory, Lake Charles, Louisiana. Adults were initially maintained for mating and blood feeding in separate cages $38 \times 46 \times 38 \mathrm{~cm}$ at $24 \mathrm{C}$ under natural photoperiod. Since almost all males from the infected colony died as fourth instar larvae, males from an additional healthy colony were used to inseminate females.

A blood meal was provided when adults were four days old by placing guinea pigs directly into the cage. Engorged females were then removed and placed individually into half-pint screened paper containers containing a $60 \times 15 \mathrm{~mm}$ petri dish filled with water for oviposition. Females were maintained at a temperature of $24 \mathrm{C}$ and relative humidity of $75-80 \%$ and constantly supplied with a $5 \%$ sucrose solution as a source of carbohydrates. Blood meals were offered after each oviposition. The number of gonotrophic cycles completed and the number of eggs and percent hatch per female per gonotrophic cycle were recorded until oviposition ceased or until the female died. Records were kept on the 
time required for oviposition following each blood meal and compared with those for healthy control females.

To more fully assess the contribution of transovarial transmission to the maintenance of the microsporidium within a mosquito population, it was also necessary to determine the relative survival potential to reproductive age of congenitally infected young when compared with heal thy controls. This was done by recording female juvenile mortality and development times for individually reared egg rafts collected from these isolated females throughout their life time. Larval rearing was conducted in individual white enamel pans $(18 \times 29 \times 4.5 \mathrm{~cm})$ containing $500 \mathrm{ml}$ of well water at $25 \mathrm{C}$. The water was infused with $10 \mathrm{ml}$ of an aqueous suspension containing $1.5 \%$ of a $3: 2$ mixture of dried liver powder and brewers yeast. Larvae were fed on alternate days until all had pupated. Pupae were isolated and the number of adult females successfully emerging was tabulated. Since transmission of the parasite occurs entirely through the female line (males die as larvae), mortality rates and development times for males were disregarded.

Only a proportion of the progeny produced by an infected female during her life time receive the infection from the maternal parent. Therefore, it was necessary to determine the prevalence rate of infection among the progeny of infected females. Since the presence of infection was more easily recognizable in males and previous records for a twoyear period indicated an equal infection rate for both sexes, the prevalence rate of infection for female progeny was determined from the infection rate for sibling males produced from the same egg raft.

In all experiments, five replicates of ten females each (heal thy and infected) were conducted and the data were combined for statistical analys is. 


\section{Results and Discussion}

The effect of the microsporidian on the physiological longevity of the adult female host is presented in Table 1. A similar decline in the number of infected and healthy females completing each successive gonotrophic cycle was observed. The average number of gonotrophic cycles completed by heal thy $(3.16 \pm 0.16)$ and infected $(3.22 \pm 0.19)$ females did not differ significantly.

Overall egg production (Table 2), expressed as the average number of eggs produced by a female during her lifetime, was also statistically indistinguishable for healthy $(327.7 \pm 13.0)$ and infected (324.3

\pm 15.7 ) females. A significant reduction in the average number of eggs laid by infected females when compared to heal thy controls was observed during the first gonotrophic cycle. However, this reduction was offset by an equally significant increase in egg production by infected females during the second gonotrophic cycle.

While no detrimental effects could be observed for physiological longevity and overall fecundity, a great effect was observed in the viability of eggs produced by infected females. When compared to heal thy controls, infected eggs showed a $52 \%$ reduction in overall hatch (Table 2). This difference was found to be highly significant $(p<0.01)$. The reduction in hatch was manifest during the first three gonotrophic cycles only and the degree of hatch reduction actually attributed to the infection (\% heal thy hatch minus \% infected hatch) was reduced with each successive gonotrophic cycle.

The preoviposition period or time required to develop and lay eggs after a blood meal was not significantly different for heal thy and infected females (Table 3). 
Once hatched, juvenile females showed little or no effect from the infection. Development times (Table 3 ) and survival rates (Table 4) of congenitally infected young to reproductive age were indistinguishable from those of heal thy controls.

The prevalence rate of infection among adult female progeny produced by infected females was $90 \%$ (Table 5 ). The percentage of adult females acquiring the infection from the maternal parent declined with each successive gonotrophic cycle.

Utilizing data collected on the reproductive potential of infected females, prevalence rate of infection among progeny and survival potential to reproductive age of congenitally infected young, I determined quantitatively the contribution of transovarial transmission to the maintenance of the microsporidium in a continually breeding population of mosquitoes.

Using the above parameters, Fine (1975) proposed a model which could be used to determine the prevalence rate of infection among adults of the progeny generation where transovarial transmission was the sole mechanism for transmission of the parasite. The model is defined below:

$$
\begin{aligned}
& B_{a}^{-}=\frac{B_{a}\left[B_{a} \alpha r\left(1-B_{a}+B_{a}^{\alpha}\right)+B_{a}^{\alpha v}\left(1-B_{a}+B_{a}^{\alpha}-B_{a}^{\alpha r}\right)\right]}{B_{a}\left[B_{a} \alpha r\left(1-B_{a}+B_{a}^{\alpha}\right)+B_{a} \alpha v\left(1-B_{a}+B_{a}^{\alpha}-B_{a} \alpha r\right)\right]}+ \\
& \left(1-B_{\alpha}+B_{a}^{\alpha}-B_{a}^{\alpha r}\right)\left(1-B_{\alpha}+B_{\alpha^{\alpha}}-B_{a}^{\alpha v}\right)
\end{aligned}
$$

where:

$B_{\alpha}^{-}=$prevalence rate of infection among adult progeny

$B_{a}=$ initial prevalence rate

$r=$ maternal vertical transmission rate, the prevalence rate of infection among progeny of infected females when mated with uninfected males 
$v=$ paternal vertical transmission rate, the prevalence rate of infection among progeny of infected males when mated with uninfected females

$\alpha=$ relative fertility (number of progeny) of infected adults when compared with their uninfected peers

$\beta=$ relative survival potential (to reproductive age) of congenitally infected young when compared with uninfected young

This model assesses the contribution of transovarial transmission to the prevalence rate of infection in subsequent generations. By repeatedly substituting the solution $B_{a}^{*}$ for $B_{a}$, one can determine the prevalence rates of infection that would be found in successive generations of hosts.

In this model I began with an initial prevalence rate $\left(B_{a}\right)$ of $50 \%$ which was arbitrarily chosen. The maternal vertical transmission rate $\left(x^{2}\right)$ was 0.9 as $90 \%$ of the progeny produced by an infected female during her lifetime were themselves infected. Since transmission of the microsporidium occurs entirely through the female line, $v$, the paternal vertical transmission rate was 0 . Infected eggs showed a $52 \%$ reduction in hatch when compared to heal thy controls, therefore relative fertility of infected adults $(\alpha)$ was 0.48 . And since survival rates of congenitally infected young to reproductive age were identical to heal thy controls, relative survival potential ( $\beta$ ) was 1 .

Applying these values to the equation I generated a curve describing the levels of infection with Amblyospora sp. for a theoretical population of $\underline{\mathrm{C}}$. Salinarius where infections are maintained by transovarial transmission alone (Fig. 45). These calculations show a 
dramatic decline in infection rates of adult progeny from $50 \%$ to less than $1 \%$ within six host generations.

The $52 \%$ reduction in hatch of egg produced by infected females relative to healthy controls and the escape of $10 \%$ of the adult female progeny from infection significantly reduce the number of females capable of transmitting the parasite to subsequent generations. With each generation proportionally more healthy females are produced thus reducing the prevalence rate of infection over a period of time.

Based on these results, and assuming that values derived from laboratory studies are similar to those existing under field conditions, I can conclude that transovarial transmission, by itself, is not capable of maintaining the microsporidium in a continually breeding population of $\underline{C}$. salinarius. Some other mechanism must exist whereby the parasite can re-enter a heal thy population. 0therwise, infections would rapidly disappear.

These findings are most interesting since in host-parasite relationships of this type, transovarial transmission has been reported to be the sole mechanism by which transmission of the parasite occurs (Kellen et al., 1965; Chapman et al., 1966) and all attempts to transmit the microsporidium horizontally by feeding spores produced in male larvae back to larval hosts have been unsuccessful (Kellen and Wills, 1962a; Chapman, 1974). At the same time, infection rates, determined from field collected eggs for natural mosquito populations, have revealed values ranging from $6-17 \%$ (Kellen and Wills, 1962a; Kellen et al., 1966; Chapman et al., 1967).

Based on these reports and the data presented herein, I believe an alternate host may be infected by the larval spores and eventually bring the microsporidium back to the mosquito host. 


\section{TABLE 1}

Physiological longevity of heal thy and Amblyospora sp.infected $C$. Salinarius. Number of females completing each gonotrophic cycle.

\begin{tabular}{ccc} 
Gonotrophic cycle & Heal thy & Infected \\
\hline I & 50 & 50 \\
II & 45 & 43 \\
III & 38 & 36 \\
IV & 19 & 22 \\
V & 6 & 10 \\
\hline Overall average & $3.16 \pm 0.16$ & $3.22 \pm 0.19^{\mathrm{b}}$ \\
\hline
\end{tabular}

average/female $\pm S . E$.

${ }^{b}$ Not statistically different from heal thy mean. 


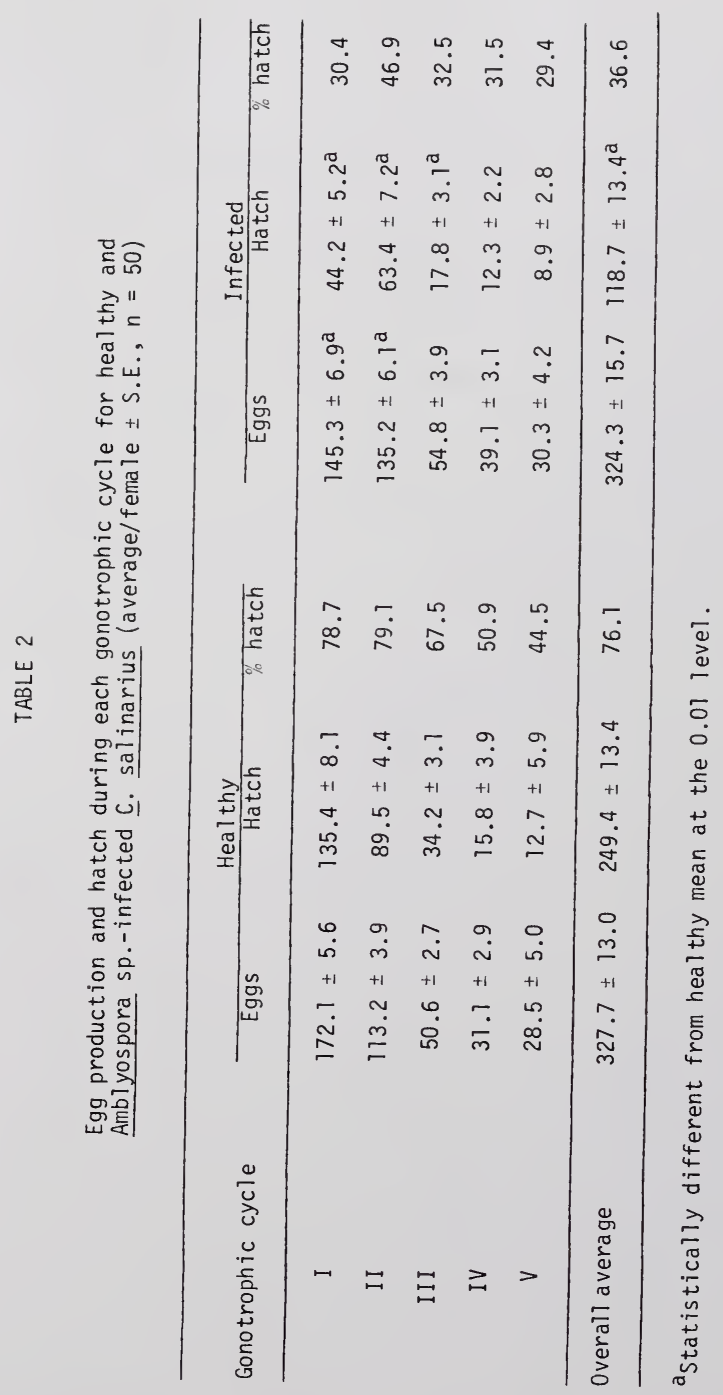


TABLE 3

Developmental periods for heal thy and Amblyospora sp.infected $\underline{C}$. Salinarius (average days/female \pm S.E.)

\begin{tabular}{lccc}
\hline & $\begin{array}{c}\text { No. of } \\
\text { observations }\end{array}$ & $\begin{array}{c}\text { Juvenile } \\
\text { development } \\
\text { period }\end{array}$ & $\begin{array}{c}\text { Preoviposition } \\
\text { period }\end{array}$ \\
\hline Heal thy & 158 & $9.45 \pm 0.10$ & $5.05 \pm 0.06$ \\
Infected & 161 & $9.51 \pm 0.09^{\mathrm{a}}$ & $5.10 \pm 0.05^{\mathrm{a}}$ \\
\hline
\end{tabular}

${ }^{a}$ Not statistically different from heal thy mean. 
TABLE 4

Survival rates for heal thy and Amblyospora sp.-infected juvenile female $\underline{C}$. salinarius expressed as the $\%$ of the total larval hatch surviving to reproductive age

(females only)

Total larval hatcha

Total no. females surviving to reproductive age

Heal thy

12,472

4,348

34.9

Infected

5,937

1,952

$32.9^{b}$

a Includes males and females and assumes $1: 1$ sex ratio.

${ }^{b}$ Not statistically different from heal thy mean. 
TABLE 5

Prevalence rate of infection among adult female progeny produced by infected females with each gonotrophic cycle

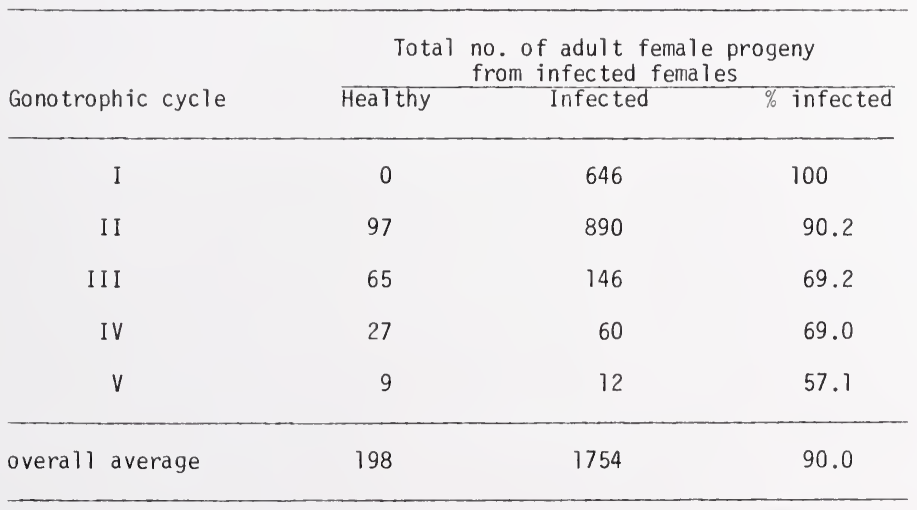




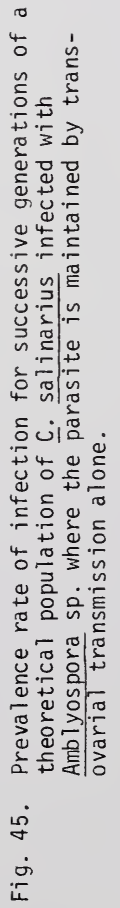




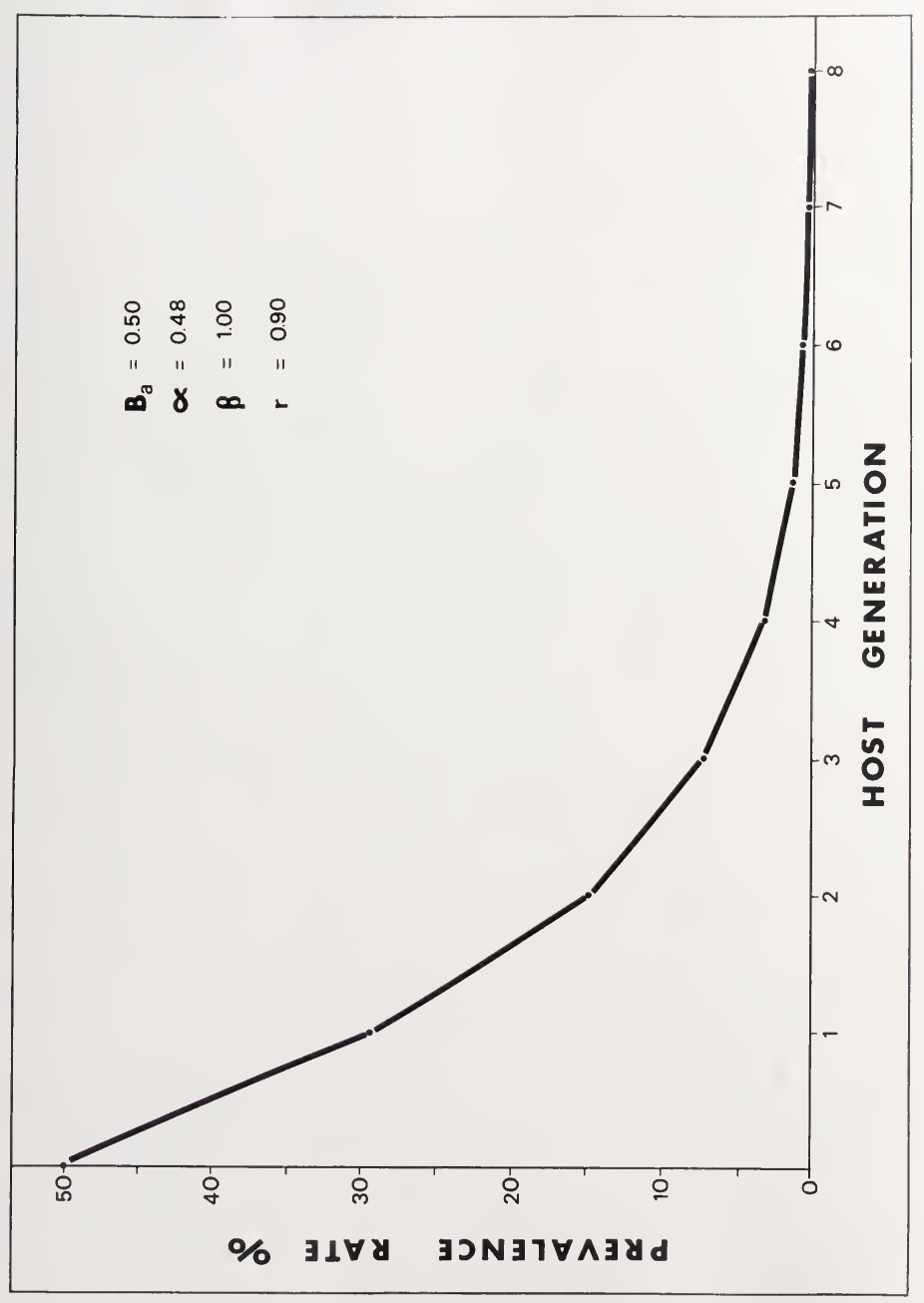




\section{REFERENCES}

Anderson, J. F. 1968. Microsporidia parasitizing mosquitoes collected in Connecticut. J. Invertebr. Pathol. 11:440-455.

Anthony, D. W., Lotzkar, M. D., and Avery, S. W. 1978. Fecundity and longevity of Anopheles albimanus exposed at each larval instar to spores of Nosema algerae. Mosq. News 38:116-121.

Anthony, D. W., Savage, K. E., and Weidhaas, D. E. 1972. Nosematosis: Its effect on Anopheles albimanus Wiedmann and a population model of its relation to mataria transmission. Proc. Helminthol. Soc. Wash., Special Is sue 39:428-433.

Brooks, W. M. 1968. Transovarian transmission of Nosema heliothidis in corn earworm, Heliothis zea. J. Invertebr. Pathol. 11:510-512.

Brooks, W. M. 1973. Protozoa: host-parasite-pathogen interrelationships. Entomol. Soc. Amer. Misc. Publ. 9:105-111.

Bulnheim, H. P. 1975. Microsporidian infections of amphipods with special reference to host-parasite relationships: a review. Mar. Fish. Rev. 37:39-45.

Canning, E. U. 1971. Transmission of Microsporidia. Proc. Int. Collog. Insect Pathol., 4th:415-424.

Chapman, H. C. 1974. Biological control of mosquito larvae. Annu. Rev. Entomol. 19:33-59.

Chapman, H. C., Woodard, D. B., Clark, T. B., and Glenn, F. E. 1970. A container for the use in field studies of some pathogens and parasites of mosquitoes. Mosq. News 30:90-93.

Chapman, H. C., Woodard, D. B., Kellen, W. R., and Clark, T. B. 1966. Host-parasite relationship of Thelohania associated with mosquitoes in Louisiana (Nosematidae:Microsporidia). J. Invertebr. Pathol. 8: $452-456$.

Chapman, H. C., Woodard, D. B., and Peterson, J. J. 1967. Pathogens and parasites in Louisiana. Culicidae and Chaoboridae. Proc. 54 th Ann. Meet. New Jersey Mosq. Extermination Assoc.: $54-60$.

Debaisieux, P. 1928. Etudes cytologiques sur quelques microsporidies. Cellule 38:389-450.

Ellis, E. A., and Avery, S. W. 1978. Resin formulations incorporating Epon 812 into a low viscosity embedding medium. Proc. Southeast Electron Microscopy Soc. 1:20. 
Fine, P. E. M. 1975. Vectors and vertical transmission: An epidemiologic perspective. Ann. N. Y. Acad. Sci. 266:173-194.

Fisher, F. M., and Sanborn, R. C. 1964. Nosema as a source of juvenile hormone in parasitized insects. Biol. Bull. 126:235-252.

Gaugler, R. R., and Brooks, W. M. 1975. Sublethal effects of infection by Nosema hel iothidis in the corn earworm, Heliothis zea. J. Invertebr. Pathol. 26:57-63.

Hagedorn, H. H. 1974. The control of vitellogenesis in the mosquito, Aedes a egypti. Amer. Zool. 14:1207-1217.

Hagedorn, H. H., Conner, J. D., Fuchs, M. S., Sage, B., Schlaeger, D. A., and Bohm, M. K. 1975. The ovary as a source of x-ecdysone in an adult mosquito. Proc. Nation. Acad. Sci. U.S.A. 72:3255-3259.

Hazard, E. I., and Chapman, H. C. 1977. Microsporidian pathogens of Culicidae (mosquitoes). In: Pathogens of Medically Important Arthropods (D. W. Roberts and M. A. Strand, eds.). Bull. W.H.O. 55 (Suppl. 1):63-77.

Hazard, E. I., Joslyn, D. J., Ellis, E. A., and Andreadis, T. G. 1978. Cytological evidence of meios is in microsporidia and its importance in taxonomy. Proc. Int. Congr. Parasitol. 4th (Abstr): (in press).

Hazard, E. I., and 01dacre, S. W. 1975. Revision of Microsporida (Protozoa) close to Thelohania, with descriptions of one new family, eight new genera and thirteen new species. U.S. Dep. Agric. Tech. Bull. 1530:104 pp.

Hazard, E. I., and Weiser, J. 1968. Spores of Thelohania in adult female Anopheles: Development and transovarial transmission, and redescriptions of T. Tegeri Hesse and T. obesa Kudo. J. Protozool. 15:817-823.

Ishihara, R. 1967. Stimuli causing extrusion of polar filaments of Glugea fumiferanae spores. Can. J. Microbiol. 13:1321-1332.

Ishihara, R. 1968. Some observations on the fine structure of sporoplasm discharged from spores of a microsporidian, Nosema bombycis. J. Invertebr. Pathol. 12:245-257.

Issi, I. V., and Maslennikova, V. A. 1964. The effect of microsporidiosis upon the diapause and survival of Apanteles glomeratus L. (Hymenoptera, Braconidae) and Pieris brassicae L. (Lepidoptera, Pieridae). Entomol. Obozyrenie 43:112-177.

Kellen, W. R., Chapman, H. C., Clark, T. B., and Lindegren, J. E. 1965. Host-parasite relationships of some Thelohania from mosquitoes (Nosematidae:Microsporidia). J. Invertebr. Pathol. 7:161-166. 
Kellen, W. R., Chapman, H. C., Clark, T. B., and Lindegren, J. E. 1966. Transovarian transmission of some Thelohania (Nosematidae:Microsporidia) in mosquitoes of California and Louisiana. J. Invertebr. Pathol. 8:355-359.

Kellen, W. R., and Lipa, J. J. 1960. Thelohania californica n. sp., a microsporidian parasite of Culex tarsalis Coquillett. J. Insect Pathol. 2:1-12.

Kellen, W. R., and Wills, W. 1962a. The transovarian transmission of Thelohania californica Kellen and Lipa in Culex tarsal is Coquillett. J. Insect Pathol. 4:321-326.

Kellen, W. R., and Wills, W. 1962b. New Thelohania from California mosquitoes (Nosematidae:Microsporidia). J. Insect. Pathol. 4:41-56.

Kramer, J. P. 1959. Some relationships between Perezia pyraustae Paillot (Sporozoa, Nosematidae) and Pyrausta nubilalis Hubner (Lepidoptera, Pyralidae). J. Insect Pathol. 1:25-33.

Krinsky, W. L. 1977. Nosema parkeri sp. n., a microsporidian from the argasid tick Ornithodoros parkeri Cooley. J. Protozool. 24:52-56.

Kudo, R. 1924. Studies on microsporidia parasitic in mosquitoes, III. On Thelohania legeri Hesse (= Th. illinoisensis Kudo, 1921). Arch. Protistenkd. 49:147-162.

Laigo, F. M., and Tamashiro, M. 1967. Interactions between a microsporidian pathogen of the lawn armyworm and the hymenopterous parasite Apanteles marginiventris. J. Invertebr. Pathol 9:546-554.

Lipa, J. J. 1957. Observations on development and pathogenicity of the parasite of Aporia crataegi L. (Lepidoptera) - Nosema aporiae n. sp. Acta Parasitol. Polonica 5:559-584.

Lipa, J. J. 1963. Studia inwazjólogiczne i epizootiologiczne nad kilkoma gatunkami pier wotniaków z rzedu Microsporidia pasozytujacymi w owadach. Prace Naukowe Instytutu Ochrony Roslin 5:103-165.

Lom, J., and Corliss, J. 0. 1967. Ultrastructural observations on the development of the microsporidian protozoon Plistophora hyphessobryconis Schaperclaus. J. Protozool. 14:141-152.

Lom, J., and Vavra, J. 1963. The mode of sporoplasm extrusion in microsporidian spores. Acta Protozool. 1:81-89.

Loubès, C., Maurand, J., Rousset-Galangau, M., and Grassé, P. 1976. Présence de complexes synaptonématiques dans le cycle biologique de Gurleya chironomi Loubès et Maurand, 1975: un argument en faveur d'une sexualité chez les microsporides? C. R. Acad. Sci. Paris 282: 1025-1027. 
Maurand, J. 1966. Plistophora simulii (Lutz et Splendore 1904), microsporidie parasite des larves de Simulium; cycle, ultrastructure, ses rapports avec Thelohania bracteata (Strickland, 1913). Bull. Soc. Zool. France 97:621-630.

Maurand, J., and Loubès, C. 1973. Recherches cytochimiques sur quelques microsporidies. Bull. Soc. Zool. France 98:373-383.

Mercier, L. 1909. Contribution l'etude de la sexualité chez les microsporidies. Mem. Acad. R. Belg. Classe Sci. 2:1-52.

Nordin, G. L. 1975. Transovarial transmission of a Nosema sp. infecting Malacosoma americanum. J. Invertebr. Pathol. 25:221-228.

Ohshima, K. 1964. Stimulative or inhibitive substance to evaginate the polar filament of Nosema bombycis Nageli. I. The case of artificial buffer solution. Japan. J. 2001. 14:209-229.

Peracchia, C., and Mittler, B. S. 1972. Fixation by means of gluteraldehyde-hydrogen peroxide reaction products. J. Cell. Biol. 53:234-238.

Reynolds, D. G. 1970. Laboratory studies of the microsporidian Plistophora culicis (Weiser) infecting Culex pipiens fatigens Wied. ButT. Entomot. Res. 60:339-349.

Reynolds, D. G. 1971. Parasitization of Culex fatigens by Nosema stegomyiae. J. Invertebr. Pathol. 18:429.

Reynolds, E. S. 1963. The use of lead citrate at high pH as an electronopaque stain in electron microscopy. J. Cell Biol. 17:208-211.

Roth, T. F., and Porter, K. R. 1964. Yolk protein uptake in the oocyte of the mosquito Aedes aegypti L. J. Cell Biol. 20:313-332.

Sprague, V. 1977. Classification and phylogeny of the Microsporidia. In: "Comparative Pathobiology" (L. A. Bulla, Jr. and T. C. Cheng, eds.), Vol. 2, Systematics of the Microsporidia, pp. 1-30. Plenum Press, New York.

Sprague, V., and Vernick, S. H. 1968. The Golgi complex of microsporida and its role in spore morphogenesis. Amer. Z0ol. 8:823-824.

Sprague, V., and Vernick, S. H. 1969. Light and electron microscope observations on Nosema nelsoni Sprague, 1950 (Microsporida, Nosematidae) with particuTar reference to its Golgi complex. J. Protozool. 16:264-271.

Spurr, A. R. 1969. A low-viscosity epoxy resin embedding medium for electron microscopy. J. Ul trastruct. Res. 26:31-43.

Tanada, Y. 1955. Field observations on a microsporidian parasite of Pieris rapae (L.) and Apanteles glomeratus (L.). Proc. Hawaii. Entomol Soc. 15:609-616. 
Thompson, H. M. 1958. The effect of a microsporidian parasite on the development, reproduction, and mortality of the spruce budworm, Choristoneura fumiferana (Clem.). Can. J. Zool. 36:499-511.

Undeen, A. H., and Alger, N. E. 1975. The effect of the microsporidan, Nosema algerae, on Anopheles stephensi. J. Invertebr. Pathol. 25:19-24.

Vávra, J. 1964. Some recent advances in the study of microsporidian spores. Proc. Int. Congr. Parasitol. 1st:443-444.

Vávra, J. 1965. Étude au microscope electronique de la morphologic et du developpement de quelques microsporidies. C. R. Acad. Sci. Paris 261:3467-3470.

Vávra, J. 1967. Hydrolyse enzymatique des spores de microsporidies. J. Protozool. 14:205.

Vavra, J. 1968. Ultrastructural features of Caudospora simulii Weiser (Protozoa, Microsporidia). Folia Parasitol. 15:1-9.

Vávra, J. 1976a. Structure of the Microsporidia. In: "Comparative Pa thobiology" (L. A. Bulla, Jr. and T. C. Cheng, eds.), Vol. I, Biology of the Microsporidia, pp. 1-85. Plenum Press, New York.

Vavra, J. 1976b. Development of the Microsporidia. In: "Comparative Pathobiology" (L. A. Bulla, Jr. and T. C. Cheng, eds.), Vol. 1, Biology of the Microsporidia, pp. 87-109. Plenum Press, New York.

Veber, J., and Jasic, J. 1961. Microsporida as a factor in reducing the fecundity in insects. J. Insect Pathol. 3:103-111.

Vernick, S. H., Sprague, V., and Krause, D. 1977. Some ultrastructural and functional aspects of the Golgi apparatus of Thelohania sp. (Microsporida) in the shrimp Pandalus jordani Rathbun. J. Protozool : 24:94-99.

Weidner, E. 1972. Ul trastructural study of microsporidian invasion into cells. Z. Parasitenk. 40:227-242.

Weidner, E. 1976. Some aspects of microsporidian physiology. In: "Comparative Pathobiology" (L. A. Bulla, Jr. and T. C. Cheng, eds.), Vol. 1, Biology of the Microsporidia, pp. 111-126.

Weiser, J. 1963. Sporozoan infections. In "Insect Pathology an Advanced Treatise" (E. A. Steinhaus, ed.), Vol. 2, pp. 291-334. Academic Press, New York.

Weiser, J. 1969. Immunity of insects to Protozoa. In "Immunity to Parasitic Animals" (G. J. Jackson, R. Herman, and I. Singer, eds.), Vol. 1, pp. 129-147. Appleton-Century-Crofts, New York. 
Weiser, J. 1976. Microsporidia in invertebrates: Host-parasite relations at the organismal level. In "Comparative Pathobiology" (L. A. Bulla, Jr. and T. C. Cheng, eds.), Vol. 1, Biology of the Microsporidia, pp. 163-201.

Weiser, J. 1977. Contribution to the classification of microsporidia. Vestn. Cesk. Spol. Zool. 24:308-320.

Windels, M. B., Chiang, H. C., and Fugala, B. 1976. Effects of Nosema pyrausta on pupa and adult stages of the European corn borer Ostrinia nubilalis. J. Invertebr. Pathol. 27:239-242.

Zimmack, H. L., Arbuthnot, K. D., and Brindley, T. A. 1954. Distribution of the European corn borer parasite Perezia pyraustae, and $i$ ts effect on the host. J. Econ. Entomol 47:641-645.

Zimmack, H. L., and Brindley, T. A. 1957. The effect of the protozoan parasite Perezia pyraustae Paillot on the European corn borer. J. Econ. Entomot. 50:637-640. 


\section{BIOGRAPHICAL SKETCH}

Theodore G. Andreadis was born on March 22, 1950, in Chelsea, Massachusetts. He attended secondary school in Hanover, Massachusetts, and graduated in 1968. In September of the same year, he entered the University of Massachusetts at Amherst. He received the Bachelor of Science degree in Fisheries Biology in 1972.

In January of 1973 he began his graduate studies in Entomology at the University of Massachusetts under the direction of Dr. Donald W. Hall. Here, he served as a graduate research assistant studying the defense reactions of mosquitoes to nematode parasites and received the Master of Science degree in January 1975.

Following the completion of his studies at the university, he joined the staff of the Cape Cod Museum of Natural History in Brewster, Massachusetts, where he served as a field naturalist and education instructor.

In September 1975 he entered the Department of Entomology and Nematology at the University of Florida and began his doctoral studies. During this time he served as a graduate research and teaching assistant and was the recipient of the Entomological Society of America's Southeastern Branch Student Award.

He has recently accepted a position at the Connecticut Agricultural Experiment Station in New Haven, Connecticut, and plans to continue research in the field of insect pathology. 
He holds membership in the Society of Sigma Xi, the American Association for the Advancement of Science and the Entomological Society of America . 
I certify that I have read this study and that in my opinion it conforms to acceptable standards of scholarly presentation and is fully adequate, in scope and quality, as a dissertation for the degree of Doctor of Philosophy.

Donald W. Hall

Donald W. Hall, Chairman

Assistant Professor of Entomology

I certify that I have read this study and that in my opinion it conforms to acceptable standards of scholarly presentation and is fully adequate, in scope and quality, as a dissertation for the degree of Doctor of Philosophy.

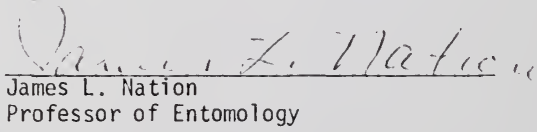

I certify that I have read this study and that in my opinion it conforms to acceptable standards of scholarly presentation and is fully adequate, in scope and quality, as a dissertation for the degree of Doctor of Philosophy.

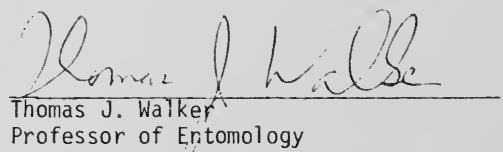


I certify that I have read this study and that in my opinion it conforms to acceptable standarás of scholarly presentation and is fully adequate, in scope and quality, as a dissertation for the degree of Doctor of Philosophy.

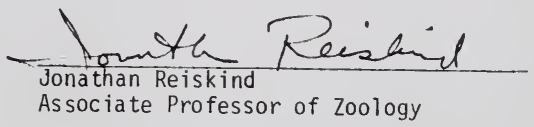

This dissertation was submitted to the Graduate Faculty of the College of Agriculture and to the Graduate Council, and was accepted as partial fulfillment of the requirements for the degree of Doctor of Philosophy.

December 1978

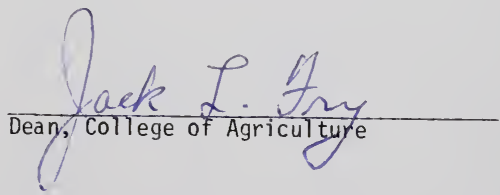

Dean, Graduate School 
